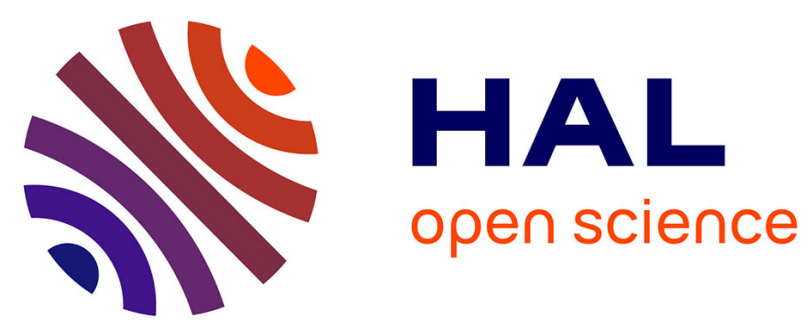

\title{
Experimentation preceding innovation in a MIS5 Pre-Still Bay layer from Diepkloof Rock Shelter (South Africa): emerging technologies and symbols
}

Guillaume E Porraz, Parkington John E., Patrick Schmidt, Bereiziat Gérald, Brugal Jean-Philippe, Dayet Laure, Igreja Marina, Christopher Miller, Viola Schmid, Chantal Tribolo, et al.

\section{To cite this version:}

Guillaume E Porraz, Parkington John E., Patrick Schmidt, Bereiziat Gérald, Brugal Jean-Philippe, et al.. Experimentation preceding innovation in a MIS5 Pre-Still Bay layer from Diepkloof Rock Shelter (South Africa): emerging technologies and symbols. 2020. hal-03087043

\author{
HAL Id: hal-03087043 \\ https://hal.science/hal-03087043
}

Preprint submitted on 23 Dec 2020

HAL is a multi-disciplinary open access archive for the deposit and dissemination of scientific research documents, whether they are published or not. The documents may come from teaching and research institutions in France or abroad, or from public or private research centers.
L'archive ouverte pluridisciplinaire HAL, est destinée au dépôt et à la diffusion de documents scientifiques de niveau recherche, publiés ou non, émanant des établissements d'enseignement et de recherche français ou étrangers, des laboratoires publics ou privés. 


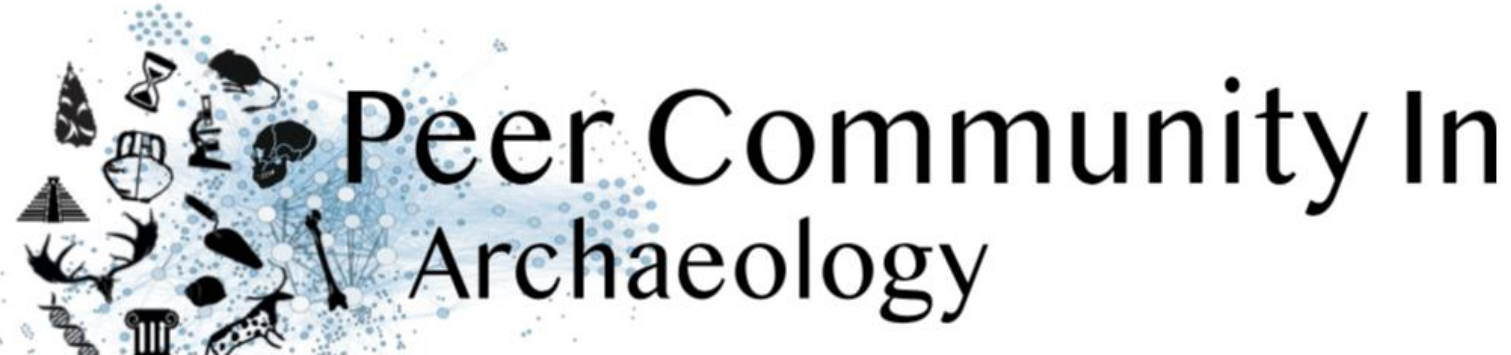

\section{RESEARCH ARTICLE}

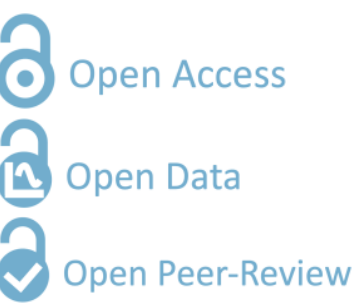

Cite as: Porraz, G., Parkington, J. E., Schmidt, P., Bereiziat, G., Brugal, J.P., Dayet, L., Igreja, M., Miller, C. E., Schmid, V. C., Tribolo, C., Val, A., Verna, C., Texier, P.-J. (2020). Experimentation preceding innovation in a MIS5 Pre-Still Bay layer from Diepkloof Rock Shelter (South Africa): emerging technologies and symbols. EcoEvoRxiv, ch53r, ver. 3 peerreviewed and recommended by $\mathrm{PCl}$ Archaeology. doi: 10.32942/osf.io/ch53r

Posted: $2020-12-17$

Recommender: Anne Delagnes

Reviewers: Enza E. Spinapolice, Kathryn Ranhorn and Francesco d'Errico

Correspondence:

guillaume.porraz@cnrs.fr

\section{Experimentation preceding innovation in a MIS5 Pre-Still Bay layer from Diepkloof Rock Shelter (South Africa): emerging technologies and symbols.}

Guillaume Porraz ${ }^{1,2}$, John E. Parkington ${ }^{3}$, Patrick Schmidt ${ }^{4,5}$, Gérald Bereiziat $^{6}$, Jean-Philip Brugal ${ }^{1}$, Laure Dayet $^{7}$, Marina Igreja ${ }^{8}$, Christopher E. Miller ${ }^{9,10}$, Viola C. Schmid ${ }^{4,11}$, Chantal Tribolo ${ }^{12,}$, Aurore Val $^{4,2}$, Christine Verna ${ }^{13}$, Pierre-Jean Texier ${ }^{1}$

\footnotetext{
${ }^{1}$ Aix Marseille Université, CNRS, Ministère de la Culture, UMR 7269 Lampea, 5 rue du Château de l'Horloge, F-13094 Aix-en-Provence, France

${ }^{2}$ University of the Witwatersrand, Evolutionary Studies Institute, Johannesburg, South Africa

${ }^{3}$ University of Cape Town, Department of Archaeology, Cape Town, South Africa

${ }^{4}$ Eberhard Karls University of Tübingen, Department of Early Prehistory and Quaternary Ecology, Schloss Hohentübingen, 72070 Tübingen, Germany

${ }^{5}$ Eberhard Karls University of Tübingen, Department of Geosciences, Applied Mineralogy, Wilhelmstraße 56, 72074 Tübingen, Germany.

${ }^{6}$ Université de Bordeaux, UMR CNRS 5199 PACEA, F-33615 Pessac, France

${ }^{7}$ CNRS-Université Toulouse Jean Jaurès, UMR 5608 TRACES, F-31058 Toulouse, France

${ }^{8}$ LARC DGPC, Ministry of Culture (Portugal) / ENVARCH Cibio-Inbio

${ }^{9}$ Eberhard Karls University of Tübingen, Institute for Archaeological Sciences \& Senckenberg Center for Human Evolution and Paleoenvironment, Rümelinstr. 23, 72070 Tübingen, Germany

${ }^{10}$ University of Bergen, SFF Centre for Early Sapiens Behavior (SapienCE), Sydnesplasses 12/13, 5020 Bergen, Norway

${ }^{11}$ Université Paris Ouest Nanterre La Défense, UMR 7041, Equipe AnTET, Nanterre Cedex, France

${ }^{12}$ CNRS, Université Bordeaux Montaigne, UMR 5060 IRAMAT-CRP2A, F-33600 Pessac, France

${ }^{13}$ CNRS, Muséum d'histoire naturelle, UMR 7194 HNHP, Musée de l'Homme, F-75016, Paris
} 


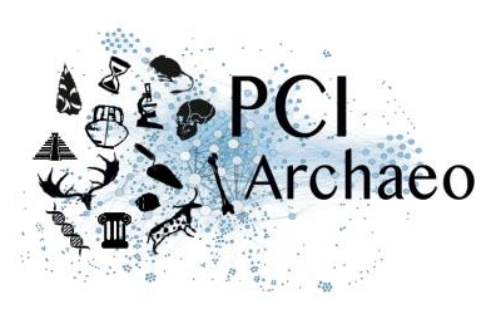

\begin{abstract}
In southern Africa, key technologies and symbolic behaviors develop as early as the later Middle Stone Age in MIS5. These innovations arise independently in various places, contexts and forms, until their full expression during the Still Bay and the Howiesons Poort. The Middle Stone Age sequence from Diepkloof Rock Shelter, on the West Coast of the region, preserves archaeological proxies that help unravelling the cultural processes at work. This unit yields one of the oldest abstract engraving so far discovered in Africa, in the form of a rhomboid marking on the cortical surface of an ungulate long bone shaft. The comprehensive analysis of the lithic artefacts and ochre pieces found in association with the engraved bone documents the transport of rocks over long distance $(>20 \mathrm{~km})$, the heat treatment of silcrete, the coexistence of seven lithic reduction strategies (including the production of bladelets and the manufacture of unifacial and bifacial points), the use of adhesives and the processing of ochre. At Diepkloof, the appearance of engraving practices take place in a context that demonstrates a shift in rock procurement and a diversification in lithic reduction strategies, suggesting that these behavioral practices acted as a cultural answer to cope with new environmental and/or socio-economic circumstances. We argue that the innovations later found during the Still Bay and the Howiesons Poort were already in the making during the MIS5 pre-Still Bay, though not all the benefits were yet taken advantage of by the populations.
\end{abstract}

Keywords: Late Pleistocene, Middle Stone Age, behavioral evolution, early symbols, bone engraving, cultural exaptation, heat treatment.

\title{
1. Introduction
}

From ca. 300,000 years onwards, the African continent experienced the development of the Middle Stone Age (MSA), a period that document the emergence of practices that are defining features of modern huntergatherers' societies (e.g. Bouzzougar et al., 2007; Conard, 2008; Henshilwood et al., 2002, 2004; McBrearty and Brooks, 2000; Wadley, 2015; Watts et al., 2016). The onset of many of these new practices took place independently during the Marine Isotopic Stage (MIS) 5 in northern and southern Africa.

Over the past three decades, southern Africa has witnessed major archaeological discoveries, highlighting the uniqueness and the significance of this part of the world in understanding how human societies transformed during the Late Pleistocene. MSA groups from Southern Africa worked stones and ochre that were transported over long distances, documenting a deep understanding of their territorial resources (Dayet et al., 2016; Porraz et al., 2013a). They were controlling fire and using it as a tool to clean living surfaces, make adhesives and heat treat rocks, thus demonstrating their ability to perform abstract thought, reflect cognitive fluidity and practice multi-tasking (Brown et al., 2009; Charrié-Duhaut et al. 2013; Schmidt et al., 2015; Wadley, 2010; Wadley et al., 2011). They worked bones and shaped tools in a fashion that was shared between different groups, supporting the existence of intelligible norms and inter-regional networks (Archer et al., 2016; d'Errico and Henshilwood, 2007; d'Errico et al. 2012a; Porraz et al., 2013a, 2018; Soriano et al., 2015). They perforated marine shells to be used as ornaments, exploited felids for their fur and depicted geometric forms on utilitarian and nonutilitarian objects, all diverse proxies illustrating the abilities of MSA groups to integrate and transform natural elements into a new culturally encapsulated environment (e.g. Henshilwood et al., 2002, 2004, 2018; Texier et al., 2010; Val et al., 2020; Vanhaeren et al., 2013).

These new behaviors emerging from the MIS5 on in southern Africa did not appear all at once but separately and in different ecological, geological and technological contexts. The oldest lines of evidence of these new 


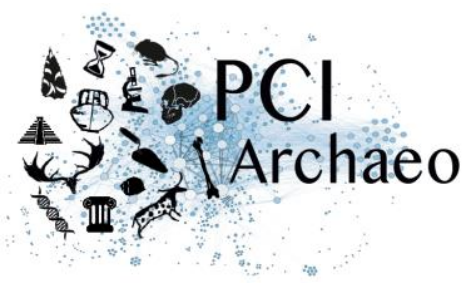

practices includes notching at the site of Klasies River (d'Errico and Henshilwood, 2007; Singer and Wymer, 1982) and engravings at the site of Blombos Cave (Henshilwood et al., 2009), laminar technologies at Klasies River and Sibudu Cave (Schmid et al., 2019; Wurz, 2002), new formal tool types such as end-scrapers at Bushman Rock Shelter (Porraz et al., 2018), and bone tools and use of pressure flaking at Sibudu Cave and Blombos Cave (d'Errico et al., 2012a; Mourre et al., 2010; Rots et al., 2017). However, it is only during the Still Bay (SB) and the following Howiesons Poort (HP) that these technological and symbolic innovations seem to merge, becoming entangled into a social system similar to the one supposedly prevailing amongst Later Stone Age populations.

In southern Africa, not only do these innovations emerge at different times, but their appearance and development do not present any chronological consistencies or spatial confinements. In order to address asynchronies and geographic discontinuities in the emergence of innovations, d'Errico and Colagé (2018) recently reintroduced the concepts of cultural exaptation, cultural neural reuse and cultural transmission, unifying different plausible mechanisms at work in the evolution of modern culture. From an archaeological perspective, the challenge is to pinpoint the contexts where those innovations took place.

An innovation is an invention, i.e. a problem-solving practice, which is adopted by a population and successfully diffused within the group and beyond. The process of invention is tied up between internal driving forces (determined by the structures) and external driving forces (oriented by the circumstances) (Boëda, 2013; Gille, 1978; Simondon, 2005). Inventions predominantly work by incremental modification or recombination of elements (Lemonnier, 1993; Roux, 2010), and often appear out of fortuitous circumstances such as mistakes in replicating information or transfers from pre-existing technologies (de Beaune, 2004; Kuhn, 2012). It has for example been proposed that the discovery of the bow-and-arrow may have benefited from the pre-existing snare-trap technology (Lombard and Phillipson, 2010). This process of cultural exaptation (de Beaune, 2012; Gamble, 1999; Gould and Vrba, 1992), which defines a stage of pre-existence, points to analogical reasoning as a key mechanism in human creativity. However, to become an innovation, the invention requires an audience (de Beaune, 2012; Kuhn, 2012). If the pre-existing social and demographic structures are appropriate (see: Shennan, 2001), the invention will percolate vertically (between generations) and horizontally (between people). Innovations exist first as a collective and social phenomenon with communication and transmission as prerequisites (see: Henrich, 2015; Henrich and McElreath, 2003; Foley and Mirazon Lahr, 2016; Mesoudi, 2016; Mesoudi et al., 2004; Stuart-Fox, 2015).

In the present paper, we develop a model based on the long and well-stratified MIS5-4 sequence of Diepkloof Rock Shelter (subsequently Diepkloof) in South Africa. We present new results from the Stratigraphic Unit (SU) Lynn that immediately precedes the SB at the site. Our new data from the Pre-SB Lynn document a set of innovative behaviors that were yet not recognized (Porraz et al., 2013; 2014), such as the engraving of geometric form(s), the heat-treatment of silcrete, the production of bladelets, the manufacture of bifacial pieces and the use of adhesive. At Diepkloof, all these novelties appear and aggregate to each other's for the first time during this single chrono-stratigraphic event. We defend that later innovations characterizing the SB and the HP were then already in the making during the MIS5 pre-SB, though innovations were manipulated differently through time. We argue that these new practices appeared in a context of socio-economic change that fostered experimentation -i.e. the benefit of testing new ideas and of gaining experiences out of new practices- as a cultural answer to face new circumstances. 


\section{The archaeological sequence of Diepkloof Rock Shelter and the Stratigraphic Unit Lynn}

Diepkloof is a large rock shelter located on the West Coast of South Africa about $200 \mathrm{~km}$ north of Cape Town (Parkington et al., 2013) (Fig. 1). It belongs to the Fynbos Biome of the Cape floristic region and opens in a local environment characterized by different ecological niches. The shelter dominates the Verlorenvlei and its coastal, partly saline lake at an altitude of about $150 \mathrm{~m}$ a.s.l. It is presently positioned $15 \mathrm{~km}$ east of the Atlantic shoreline and of the neighboring site of Elands Bay Cave (Parkington and Porraz, 2016).

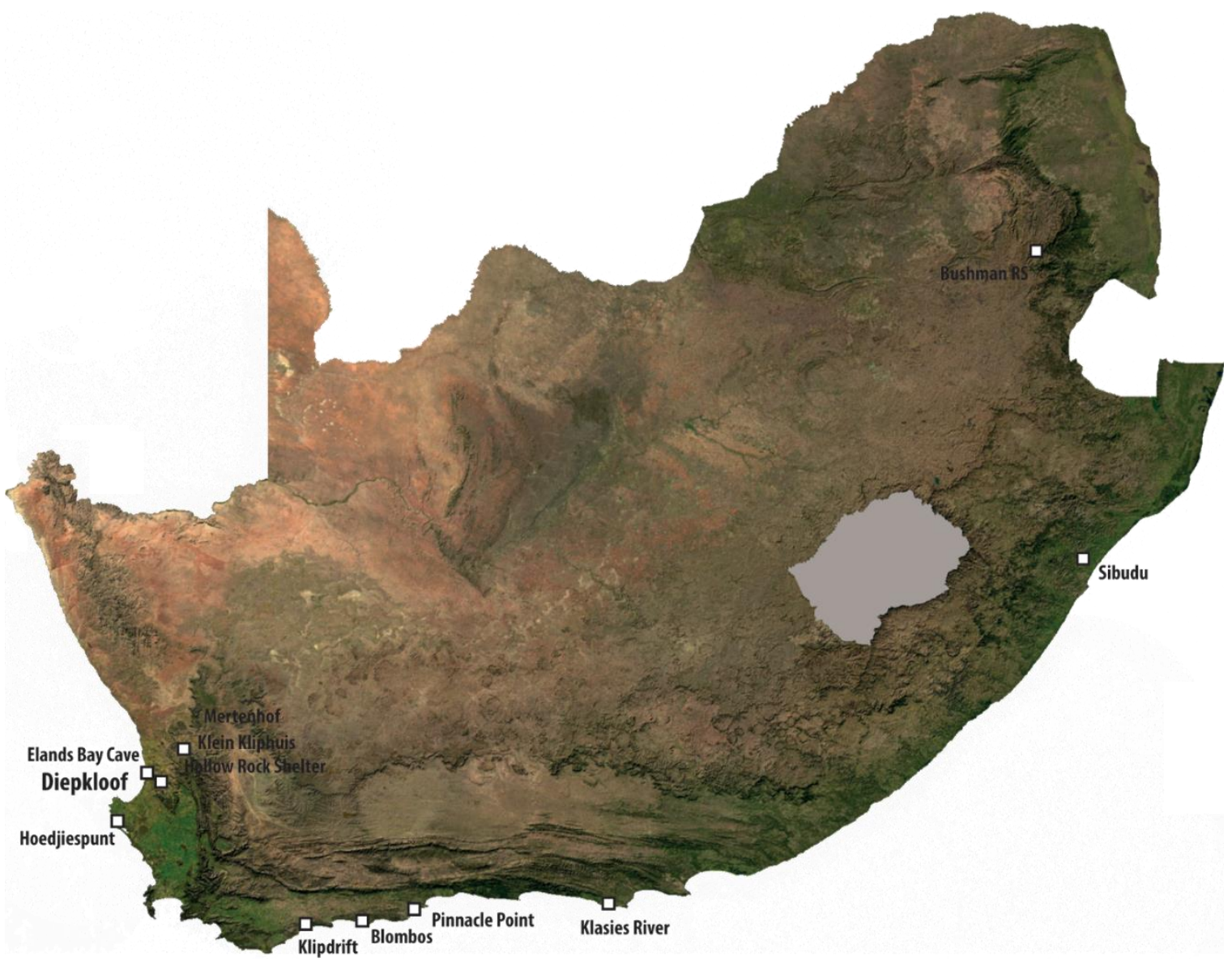

Figure 1. Map of South Africa with location of Diepkloof Rock Shelter and of the MSA sites mentioned in the text

Excavations at Diepkloof started in 1998 and revealed a 3 m long MSA sequence without reaching bedrock. The site records occupations covering MIS5 and MIS4, without significant sedimentary hiatuses (Miller et al., 2013). Technological descriptions allow a subdivision of the archaeological sequence into five main phases (Porraz et al., 2013a) that include SB and HP occupations. In recent papers, we employed various proxies to recognize the HP as a main period of technological innovations at the site (Porraz et al., 2013b). Such proxies include the transport of raw materials over a distance greater than $20 \mathrm{~km}$, their deliberate heat treatment, the production of small blades, their transformation into geometric forms and their insertion into composite tools using adhesive (Charrié-Duhaut et al., 2013; Igreja and Porraz, 2013; Schmidt et al., 2013). Of particular 


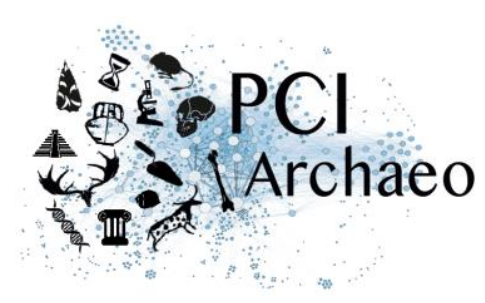

significance was the discovery of hundreds of engraved shell fragments, all parts of ostrich eggshell containers that were marked according to a narrow range of geometric motifs (Texier et al., 2010, 2013). We hypothesized that the HP represented a change in the way the site was occupied and in the way groups were organized at a larger geographical scale (Porraz et al., 2013b).

The last excavations at Diepkloof occurred in 2012 and 2013 and focused on the lower deposits, namely the SB and earlier occupations. In the present paper, we focus on the pre-SB SU Lynn that has been excavated over a surface of ca. $4.5 \mathrm{~m}^{2}$ (Fig. 2). The SU Lynn was directly dated by Optically Stimulated Luminescence (OSL) to $100 \pm 10$ ka by Tribolo et al. (2013) and has been bracketed to between $88.4 \pm 4.0$ (SU Marc) and $76.5 \pm 3.3$ (SU Logan) by Jacobs and Roberts $(2015,2017)$.
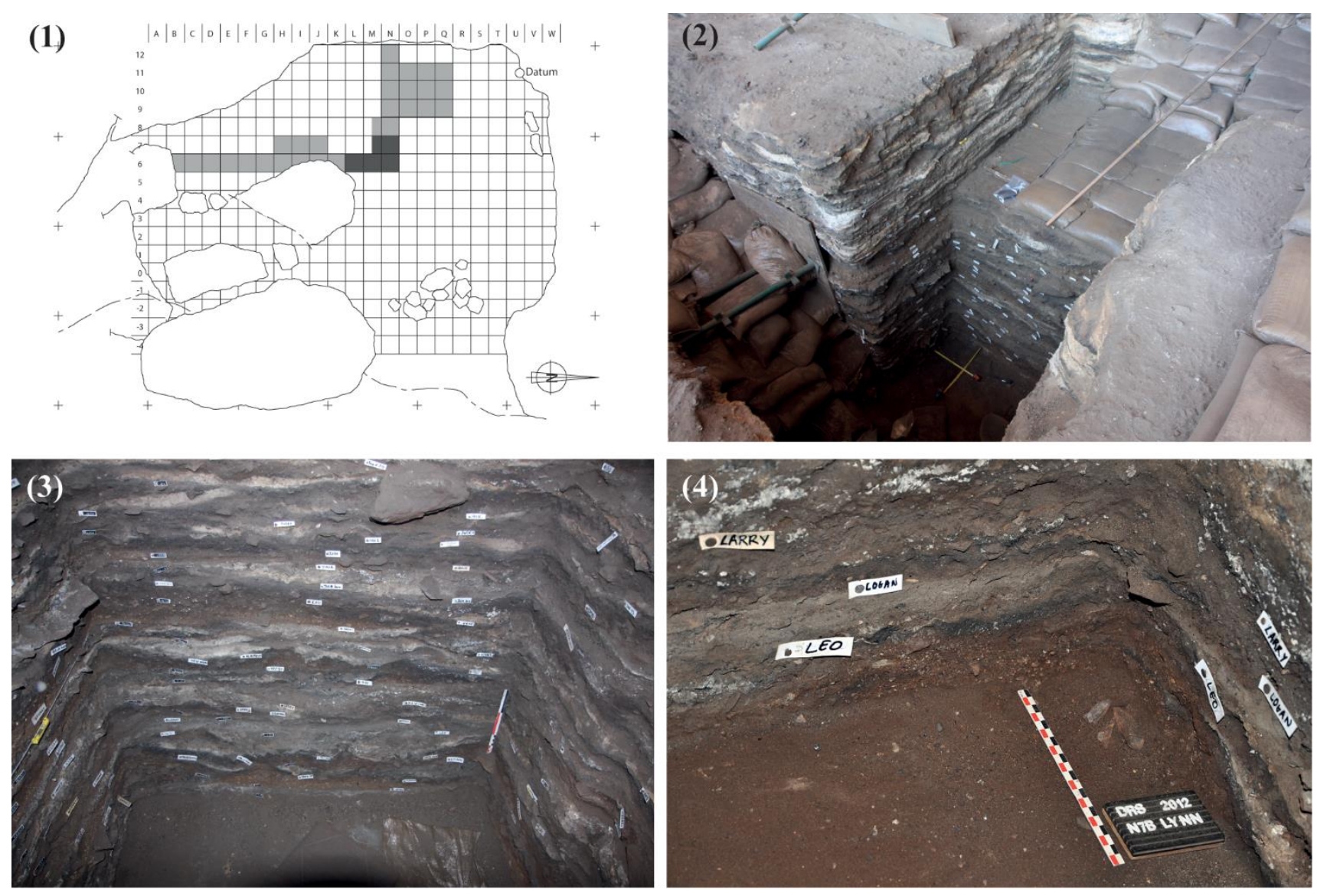

Figure 2. (1) Planimetry of Diepkloof Rock Shelter (in dark grey: squares where the stratigraphic unit Lynn has been excavated) and various photographs of the 2012-2013 excavations with detail (2) on the excavated area, (3) on the MN7/M-N8 stratigraphic profile and (4) on the engraved bone at the time of its discovery in the stratigraphic unit Lynn.

The SU Lynn belongs to the lithostratigraphic facies 2 as defined by Miller et al. (2013). This ca. $10 \mathrm{~cm}$ thick deposit is characterized by a reddish sandy silt interspersed with combustion features, in the form of ash lenses overlying charcoal. These anthropogenic components are associated with trampling that has reduced the visibility of most of these events, with the presence of surfaces that suggest short interruptions within the sedimentation. 


\section{sapper}

Botanical remains identified within the SU Lynn comprise Heeria argentea, Olea sp., Podocarpus sp. and Rapanea melanophloeos (Cartwright, 2013), which are presently found in the Cederberg mountains.

The faunal assemblage from SU Lynn is small (NISP $=141$ ) and composed of species that reflect an open habitat with limited vegetation (shrubland) as well as the presence of the Verlorenvlei, the occurrence of rocky slopes in and around the shelter and the proximity with the Atlantic Ocean coastline. Small to large bovids have been identified, with the largest species recorded (Bov size IV) being the eland Taurotragus oryx, together with equids and Rhinoceros (Steele and Klein, 2013). Non-mammalian species include the angulate tortoise Chersina angulata, snakes, a white-breasted cormorant and marine shells (limpets) (Steele and Klein, 2013; Val, 2019). Cut-marks have been noticed on two bones, respectively a large bovid femur and a large-medium bovid pubis. A few bone flakes provide evidence of marrow extraction at the site.

The study conducted by Porraz et al. (2013a) of a lithic collection originating from a surface of $2 \mathrm{~m}^{2}$ (squares M-N6) recognized the pre-SB Lynn as a distinct technological phase. The present study integrates new material and is based on a surface of $3.5 \mathrm{~m}^{2}$ (Fig. 2). It does not include the material from the original test-pit (square L6).

\section{The engraved bone from the pre-SB Lynn}

In 2012, the excavation of SU Lynn led to the discovery, in situ, of the diaphysis splinter of a large ungulate displaying grooves that intersect in a pattern indicative of a deliberate action (Fig. 3). Like for ochre, incisions on bones can have a functional cause and originate accidentally. Lithic implements used to perform butchery activities can produce linear, superficial marks, resulting from non-intentional contacts between the tool and the bone surface (Binford, 1981; Lyman, 1994). The anatomical location, orientation and dimensions of these butchery marks are directly correlated to the specific gestures applied during animal carcass processing (e.g. skinning, disarticulation, defleshing, ligament removal; Binford, 1981; Galán and Domínguez-Rodrigo, 2013; Shipman and Rose, 1983; Fisher, 1995; Soulier and Morin, 2016; White, 1992). Accidental scores can also be produced when the bone is used as a retoucher. Such scores tend to be short and perpendicular to the main axis of the bone; they are often multiple (the number varying with the intensity of use) and tend to concentrate on convex bone surfaces, intersecting each other in a mostly parallel way (e.g. Blasco et al., 2013; Mallye et al., 2012). Both types of marks, resulting from carcass processing or from the use of the bone as a retoucher, are located on the most external surface of fresh bones, namely the cortical surface covered by periosteum.

The distinction between intentional and non-intentional incisions rests on the combination of several criteria from macro- to micro-scale (e.g. Domínguez-Rodrigo et al., 2009; Maté-Gonzàles et al., 2015; Monnier and Bischoff, 2014; Olsen and Shipman, 1988; Palomeque-Gonzàles et al., 2017; Soulier and Morin, 2016). The anatomical location of the incisions, their orientation and distribution on the bone, as well as their length and cross-section are all relevant features to distinguish deliberate engravings from accidental butchery marks, including retouching scores. At a higher magnification, evidence of reiterated passages of a tool in the same incision and/or the resumption of a previous incision are additional evidence of a deliberate intention ( $d^{\prime}$ Errico and Villa, 1997; Shipman 1981). 


\section{sesp $\mathrm{PCI}$ \\ I. I Archaeo}
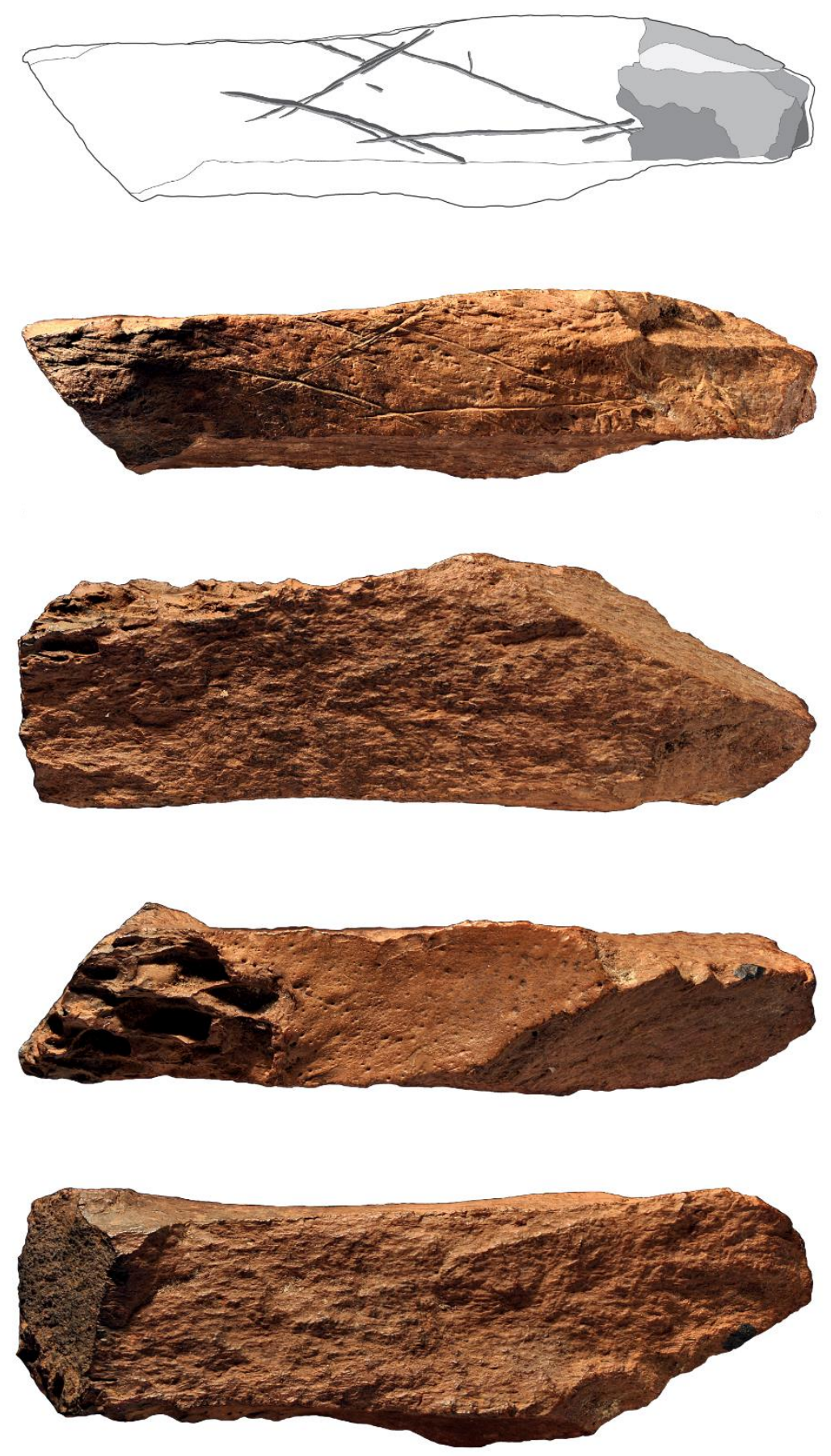

$3 \mathrm{~cm}$

Figure 3. Different views of the engraved bone from the stratigraphic unit Lynn at Diepkloof Rock Shelter with a diacritic drawing of the engraved cortical surface. 


\section{sapred}

\subsection{Anatomy, taxonomy and taphonomy of the engraved bone from SU Lynn}

The specimen is a large fragment of a thick, straight and dense mammal long bone, relatively flat, which belongs to an adult ungulate, with the following dimensions: $51.6 \mathrm{~mm}$ long and $9.6 \mathrm{~mm}$ wide. The mean of the four cortical thickness measurements is $14.3 \mathrm{~mm}$. While we cannot propose a definite taxonomical attribution, it is possible to narrow the range of plausible taxa. The presence of trabecular (spongy) bone on one side (Fig. 3 ) indicates that it is consistent with a proximal or distal part of a long bone shaft (i.e. in the metadiaphysis region). It also supports a taxonomic attribution to an artiodactyl rather than a perissodactyl, the latter often characterized by more abundant spongy bone along the medullary cavities of long bones. The large dimensions of the specimen allow us to assign it to the largest of the bovid class sizes, as defined by Brain (1974, and see: Brugal, 2017). Cortical thickness is a useful proxy for identifying ungulate class size (Morales et al., 2008; Reynard et al., 2014). Following the code established by Driver (2005), the specimen from SU Lynn falls into category 8 (14-15.99mm), further confirming its attribution to a bovid class size IV when compared to Reynard et al. (2014). Amongst extant southern African species, this class size only includes the Eland (Taurotragus oryx) and the African Buffalo (Syncerus caffer). In SU Lynn, one remain was confidently attributed to Eland and this species, today abundant in the Fynbos Biome, is well represented throughout the sequence at Diepkloof (Steele and Klein, 2013). While the African Buffalo is not documented at Diepkloof, a few remains are attributed to the extinct giant buffalo (Pelorovis antiquus), but only from the Early HP upwards (Steele and Klein, 2013).

Anatomically, the morphology, shape and external surface texture of the bone are consistent with the proximal radius, the distal tibia or the proximal or distal metapodials. We exclude the following elements, which have a different morphology and preserve softer and more abundant spongy bone than the specimen from SU Lynn: proximal/distal humerus and femur, distal radius, proximal tibia and distal metapodials.

The anatomical position, orientation, dimensions, trajectory and internal microscopic features (e.g. shape of the cross-section, presence/absence of micro-striations, herzian cones, presence/absence of a shoulder effect and a barb effect) were confronted with actualistic and archaeological data on trampling (DomínguezRodrigo et al., 2009; Fiorillo, 1989; Oliver, 1989; Olsen and Shipman, 1988), on human action on bones (e.g. butchery, portable art) (Bromage and Boyde, 1984; Cook, 1986; de Araujo Igreja, 1999; D'Errico, 1991; Domínguez-Rodrigo et al., 2010; Fritz, 1999; Juana et al., 2010; Lyman, 1987; Soulier and Morin, 2016), as well as in the comprehensive experimental referential recently published by Thiébaut et al. (2019). From a taphonomic point of view, the cortical surface of the specimen is well preserved, allowing for a direct analysis of the marks. Unlike many of the faunal remains from Diepkloof, the engraved specimen was not affected by chemical alterations and there are no signs of weathering cracks. All the edges are gently blunted. The lateral sides exhibit rough surfaces and the proximal edge presents a right angle and transverse outline, such features are consistent with dry breakage, possibly resulting from post-depositional trampling or sediment compaction (see: Villa and Mahieu, 1991). Notwithstanding, the oblique angle and V-shaped outline of the distal tip suggests that the bone was at least partly broken while still fresh. The breakage, associated with limited exfoliation, also affects the cortical surface of the bone. Blackening due to limited or indirect exposure to heat (see: Stiner et al., 1995; Clark and Ligouis, 2010) has affected both the distal and the proximal parts of the bone, as illustrated by, respectively, the presence of dark black dots and of a diffuse dark brown coloration. 


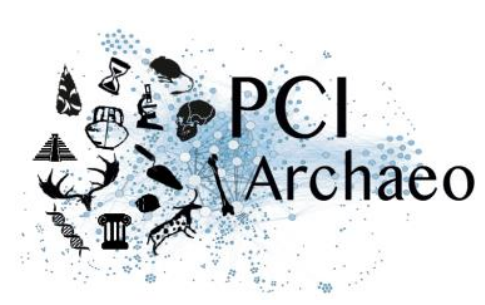

This indicates that burning occurred after breaking. We did not observe any trampling, chop marks or butchery marks on the bone.

\subsection{Characterization and interpretation of the engravings}

The engraved bone was observed and photographed using high power microscope (SEM-JEOL JSM 6460LV) to confirm the sequence and direction of the incisions at $x 10$ to $x 70$ magnifications. Of a total of six incisions visible on the fragment, four are incompletely preserved due to the breakage of the bone. The longest complete incision is $21 \mathrm{~mm}$ long while the longest incision interrupted by a break exceeds $20 \mathrm{~mm}$. Four main incisions (Fig. 4) are organized following a geometric pattern that mimics a rhomboid shape. One incision (incision 4) is parallel to the longitudinal axis of the bone while the others are oblique. The rhomboid pattern comprises two parallel lines (incisions 1 and 3 ) and two converging lines (incisions 2 and 4), intersecting at angles of $22^{\circ}$ and $45^{\circ}$, and $140^{\circ}$ and $160^{\circ}$, respectively.

The SEM observations (Fig. 4, SEM B, C, D, F) document an abrupt termination of lines 1, 1', 2' and 3, which is due to the breakage of the bone. This indicates (1) that the selected bone that was engraved was bigger than the specimen presently studied and (2) that the engravings had a larger extension than we can observe now. In particular, we suggest that the incisions $1^{\prime}$ and $2^{\prime}$ are part of a larger and possibly more complex geometric motif, with line $1^{\prime}$ being parallel to 1 and line $2^{\prime}$ being parallel to 4 . We acknowledge that parallel incisions could be the result of a reiterated passage of the same tool, as it is possibly the case for line 3 (see: Fig. 4, SEM F), although small lateral striations are sometimes present on single and unique cut-marks. Line $2^{\prime}$ extends beyond line 4 and both incisions are separated by $0.43 \mathrm{~mm}$. They could correspond to two distinct motions, but they could also be consistent with a single gesture interrupted by a change in the point of contact between the tool and the bone, something that is well documented for engravings on pebbles and bones (d'Errico 1994; $\mathrm{d}^{\prime}$ Errico and David 1993). Line 1 and line $1^{\prime}$ are relatively far apart $(1.19 \mathrm{~mm})$ and we suggest that they correspond to two distinct motions, rather than to the reiterated passage of the same tool.

SEM observations show that the cortical surface of the bone as well as the incisions are relatively fresh. The latter are well defined and well preserved, confirming the minimal impact of post-depositional damage on the engraved bone surface. The incisions are deep, relatively linear and present a smooth aspect, but are also slightly fringed and indented (Fig. 4, SEM A, D, E, F). These diagnostic features support the hypothesis that the bone was semi-fresh/partly dried at the time of its engraving.

We reconstructed the chronology of the incisions -from 1 to 4 - as well as their directionality, based on how they intersect each other, the presence of small indentations and the morphology of their extremities (following for instance: Bromage and Boyde, 1984; d'Errico et al., 1994; Fritz, 1999; Texier et al. 2010) (Fig. 4). Experimental work suggests that the starting point of a line tends to be deep and narrow, while the distal extremity tends to be larger ("fan-shape") and more superficial (e.g. de Araujo Igreja, 1999; d'Errico et al. 1994; Fritz, 1999). In addition, we considered the morphology of the indentations that characterize the external surface of the bone at the contact with the incised lines. When they occur, those indentations present asymmetric angles that we have used to infer the direction of the lines. We propose that the engraver produced the lines in a continuous rotational way, rather than as two distinct sets of parallel lines. 


\section{A. PCI
Sin. $P$ Archaeo}
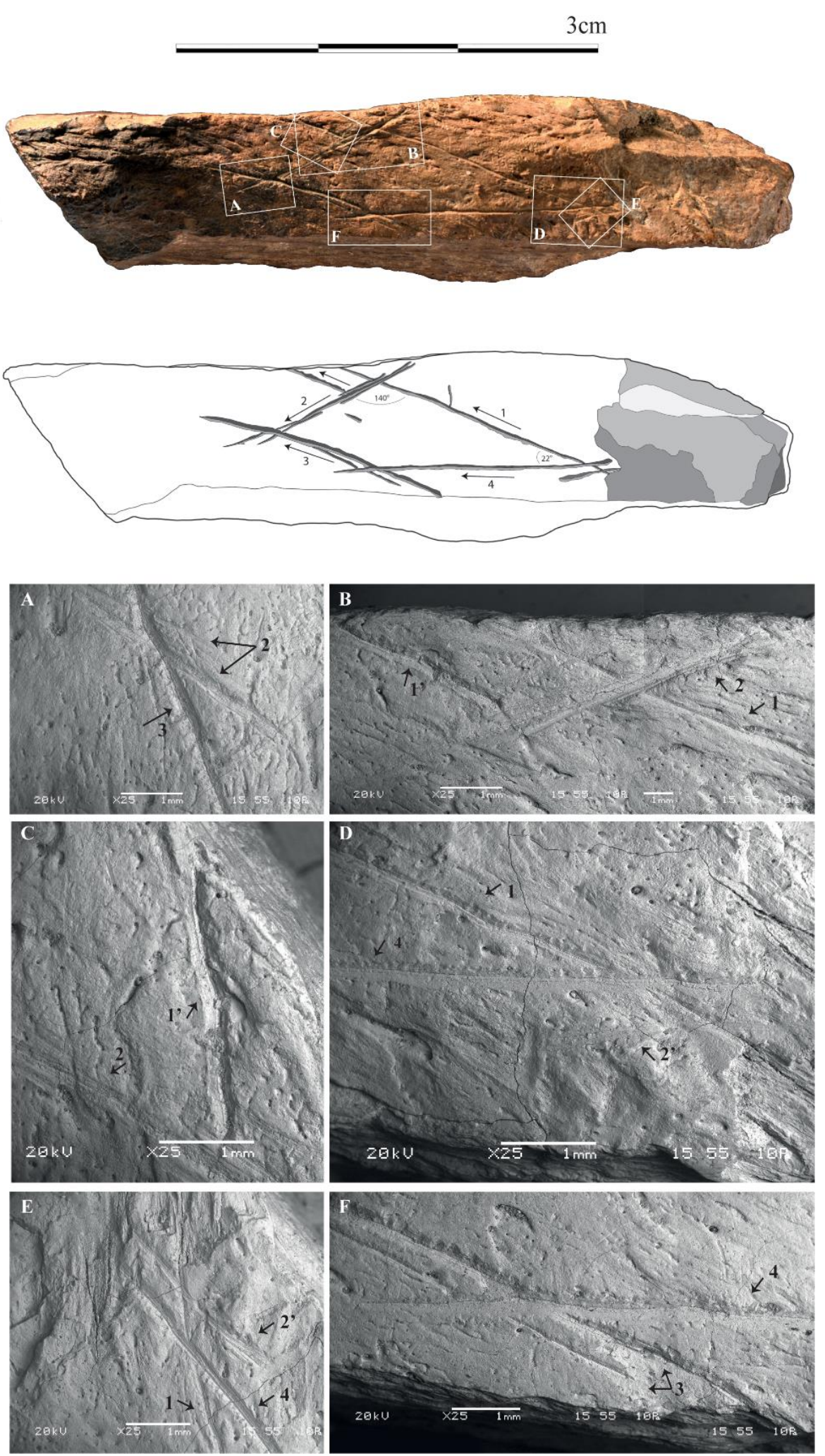

Figure 4. Details on the engraved bone from the stratigraphic unit Lynn (Diepkloof Rock Shelter). SEM pictures (A to F) are located on the photograph. On the drawing, the arrows indicate the direction of the engraving. On the drawing and the SEM pictures, the numbers ( 1 to 4 ) indicate the chronology of the incisions. 


\section{sapper}

The incisions have a general asymmetrical V-section (Fig. 4, SEM A, C, F), indicating that they originate from contact with the sharp and raw (unretouched) active part of a stone tool. However, the incisions 3 and 4 (Fig. 4, SEM D and F) are partially indented, suggesting they may originate from contact with an active part of a tool that was partially damaged or retouched. The slightly sinuous appearance of some lines and changes in the point of contact between the tool and the bone surface (e.g. line 2), which could relate to irregularities of the bone surface, are features suggesting that the active part used to engraved the bone may have been a point rather than an edge (d'Errico et al. 1994). Lines 2 and 3 are long, rectilinear incisions, both surrounded by smaller, ancillary, incisions (Fig. 4) consistent with a shoulder effect (e.g. Shipman and Rose, 1983).

No refitting could be successfully identified, which makes it difficult to elaborate on whether the bone was a utilitarian or non-utilitarian object. However, we can put forward two arguments: (1) there is no evidence of other intentional transformation or use on the engraved bone fragment and (2) so far, no worked bone was discovered within the pre-SB and SB faunal collection of Diepkloof. These arguments incline us to hypothesize that the engraved medium was a raw and non-utilitarian object. Whether the selection of a large bone reflects a deliberate selection toward a large species or toward a particularly large skeletal element remains uncertain.

Several arguments encourage us to reject the hypothesis that the incisions are randomly organized and that they result from butchering activity. On the contrary, several features support the intentional character of the engravings. Using actualistic observations on human marks (e.g. Galán and DomínguezRodrigo, 2013; Fritz, 1999; Maté-Gonzalez et al., 2015; Soulier and Morin, 2016; Thiébaut et al., 2019), we argue that the anatomical position, length and orientation of the incisions, as well as the way they intersect each other allow us to confidently exclude the possibility that they result from carcass processing activities. Defleshing marks on a distal tibia would be either long and parallel to the main axis of the bone or transverse and short. Cutmarks associated with tendon removal, in the case of metapodials, would be shorter, closer to the proximal/distal extremity and transverse. Alternatively, they could be very long and parallel to the main axis of the bone but should not intersect each other. Skinning marks on a proximal radius or on metapodials would be parallel to the bone and a single incision is usually enough to cut through the skin. Finally, disarticulation marks would be closer to the articular surface (i.e. proximal/distal epiphysis), which is missing in the case of the Diepkloof bone. Besides the fact that the organization and distribution of the engravings do not match with the "butchery hypothesis", we have to recall that the engraved bone only represents a fragment of a larger piece that had more extended engravings on its surface, though the exact extension remains uncertain. In addition, the likely use of a point to produce the engravings and the hypothesis that the bone was partly dried at the time of its engravings, are both additional arguments in favor of an intentional engraving.

The engraved fragment displays a main motif composed of four lines that form a geometric shape resembling a rhomboid. This abstract form was likely part of a broader geometric pattern, as suggested by two additional and interrupted incisions ( $1^{\prime}$ and $2^{\prime}$ ) that extend the motif in a geometry that seems to conform to the rhomboid. This engraving depicts one of the oldest geometric shapes recovered in southern Africa thus far. It matches other geometric forms recognized at Blombos Cave on ochre pieces (Henshilwood et al., 2002; 2009). 


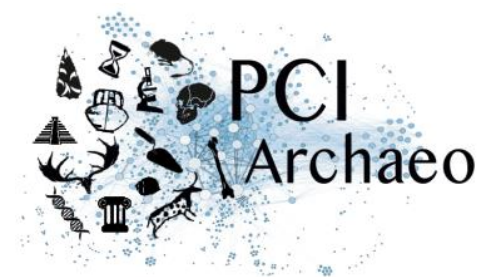

\section{Raw materials, lithic technology and mobility system during the pre- SB Lynn}

\subsection{Raw material acquisition and silcrete heat treatment}

The lithic assemblage of SU Lynn is composed of 2070 pieces, including 922 pieces with a dimension exceeding $20 \mathrm{~mm}$. In addition, 51 fragments of ochre pieces were retrieved. Energy dispersive X-ray spectrometry (SEM-EDS) and X-ray diffraction (XRD) analyses indicate that two main categories of rocks composed the ochre assemblage from SU Lynn: shale and ferricrete. Shale comes from a geological bed occurring inside the shelter and their origin in the archaeological collection is likely natural. By contrast, ferricrete and shale/ferricrete are from exogenous sources that are currently unknown (Dayet et al., 2013; 2016). Those ochres are rich in iron oxide and three of them provide clear indications that they have been worked by grinding (Fig. 5). The preferential exploitation of exogenous iron rich ochre materials is a pattern observed from SU Lynn to the post-HP (Dayet et al., 2013).

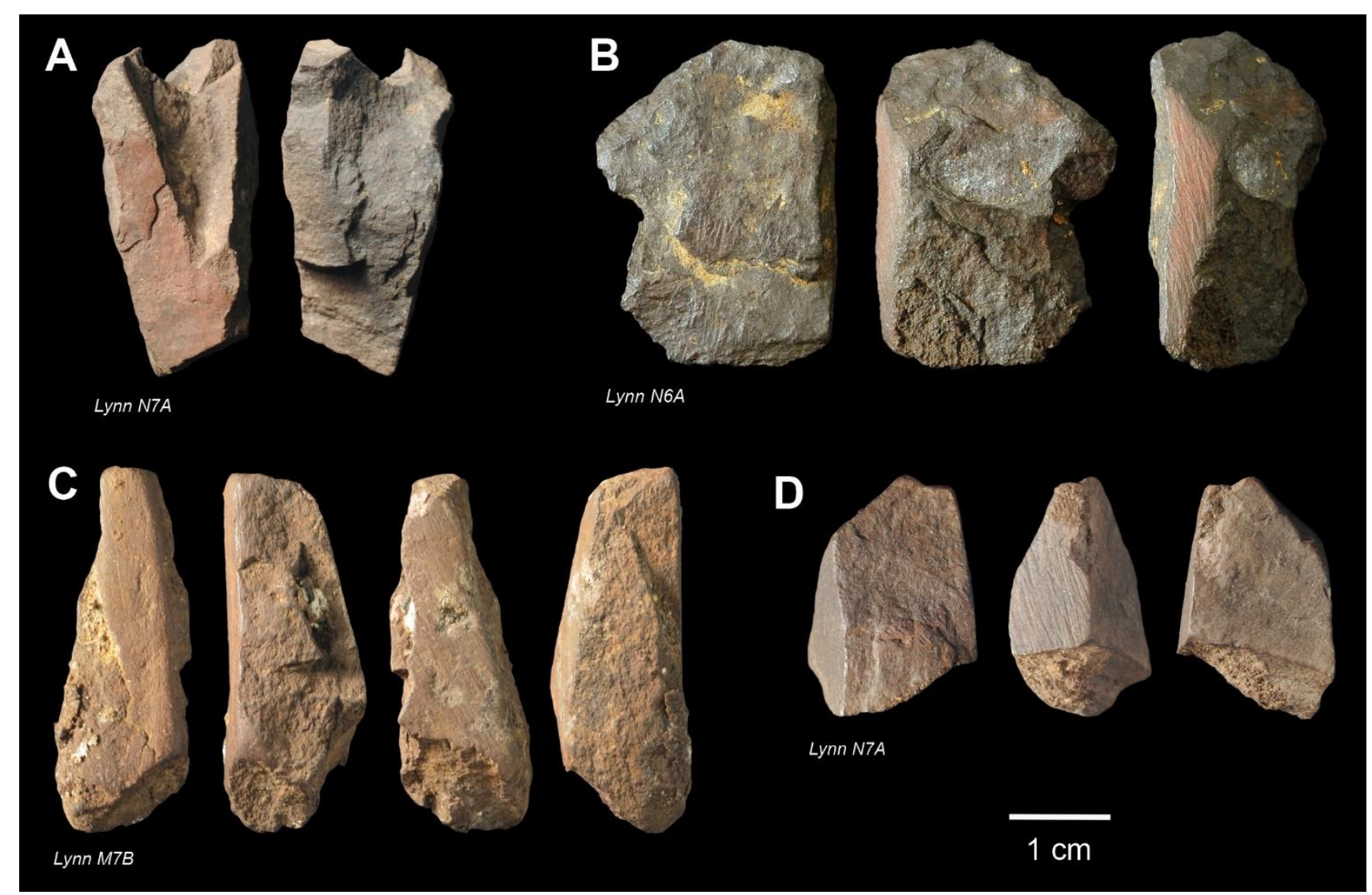

Figure 5. A selection of ochre pieces from the stratigraphic unit Lynn illustrating the variability in raw materials and degree of processing (Diepkloof Rock Shelter). A: unmodified shale fragment with a lustrous patina (of natural origin) on one face. B \& C: shale/ferricrete nodules with a ground facet. D: ferricrete nodule with three ground facets. 
The lithic assemblage of SU Lynn (Table 1) testifies the exploitation of quartzite (60.1\%) and quartz (12.8\%) but it comprises a substantial proportion of silcrete (24.7\%) as well. Hornfels and other fine-grained rocks only compose $2.4 \%$ of the lithic assemblage. Within the silcrete sample, we distinguished a coarse-grained yellowbrown variety (identified as "YB" silcrete in Porraz et al., 2013a) from finer grained varieties that dominate (75\% of the sample). Our understanding of the regional geology (see: Porraz et al., 2013a) shows that some raw materials were collected locally (i.e., quartzite, quartz and coarse-grained silcrete are available within a 10 $\mathrm{km}$ radius from the site), while the fine-grained silcrete, hornfels and other silica rocks (composing $21 \%$ of the petrographic corpus) were acquired from distances greater than $20 \mathrm{~km}$. This sample of exotic rocks presents macroscopic variability and cortical surfaces that suggest acquisition from different places and outcrops, both in alluvial terraces and in sub-primary contexts.

Table 1. Lithic assemblage from the stratigraphic unit Lynn per raw material (Diepkloof Rock Shelter) (all calculations in the text are based on products $>20 \mathrm{~mm}$ ). Formal tools are classified by their respective technological categories.

\begin{tabular}{|l|cccccccc|}
\hline & Quartzite & Quartz & Local Silcrete & Exotic Silcrete & Hornfels & Others & TOTAL (N) & TOTAL (\%) \\
\hline Flakes & 306 & 64 & 29 & 66 & 10 & 3 & 478 & 51.8 \\
Laminar flakes & 51 & 5 & 6 & 27 & 1 & 0 & 90 & 9.8 \\
Blades & 8 & 0 & 3 & 7 & 0 & 0 & 18 & 1.9 \\
Bladelets & 2 & 1 & 3 & 31 & 1 & 0 & 38 & 4.1 \\
Cores & 2 & 1 & 2 & 5 & 0 & 0 & 10 & 1.1 \\
BipolarCores & 0 & 7 & 1 & 2 & 1 & 0 & 11 & 1.3 \\
Bifacial pieces & 8 & 1 & 0 & 3 & 0 & 1 & 13 & 1.4 \\
Shaping flakes & 24 & 3 & 4 & 8 & 0 & 0 & 39 & 4.2 \\
Manuports & 1 & 1 & 0 & 0 & 0 & 0 & 2 & 0.2 \\
Fragments >20 $\mathbf{~ m m ~}$ & 152 & 35 & 8 & 22 & 4 & 2 & 223 & 24.2 \\
\hline TOTAL (N) & 554 & 118 & 56 & 171 & 17 & 6 & 922 & - \\
TOTAL (\%) & 60.1 & 12.8 & 6.1 & 18.6 & 1.8 & 0.6 & - & 100 \\
Flakes <20 $\mathbf{~ m m ~}$ & 153 & 122 & 15 & 101 & 13 & 3 & 407 & - \\
Fragments <20 $\mathbf{m m}$ & 197 & 394 & 13 & 124 & 13 & 0 & 741 & - \\
TOTAL (N) & 904 & 634 & 84 & 396 & 43 & 9 & 2070 & - \\
\hline
\end{tabular}

Our visual identification of heating parameters on 465 of the 480 silcrete pieces (see for the definition of attributes: Schmidt, 2019; Schmidt et al., 2015) shows that, depending on whether indeterminate artifacts are considered or not, $73 \%$ to $91 \%$ of the silcrete assemblage was heat-treated (Fig. 6). On $17 \%$ of the heated silcrete pieces, rough pre-heating removal scars are preserved while $7.4 \%$ show Heat-Induced Non-Conchoidal (HINC)-fracture surfaces (Table 2), pinpointing that they heat-fractured during and were further reduced after the heat treatment. Three pieces show traces of potential tempering residue, suggesting heat treatment was done in embers, as proposed by Schmidt et al. $(2015,2016)$. A few thermal fragments were recorded in the assemblage but whether heat shattering occurred as an accident during heat treatment or through postdepositional processes remains unclear in these cases. Whether heating was performed on site or prior to its introduction also remains to be demonstrated. 

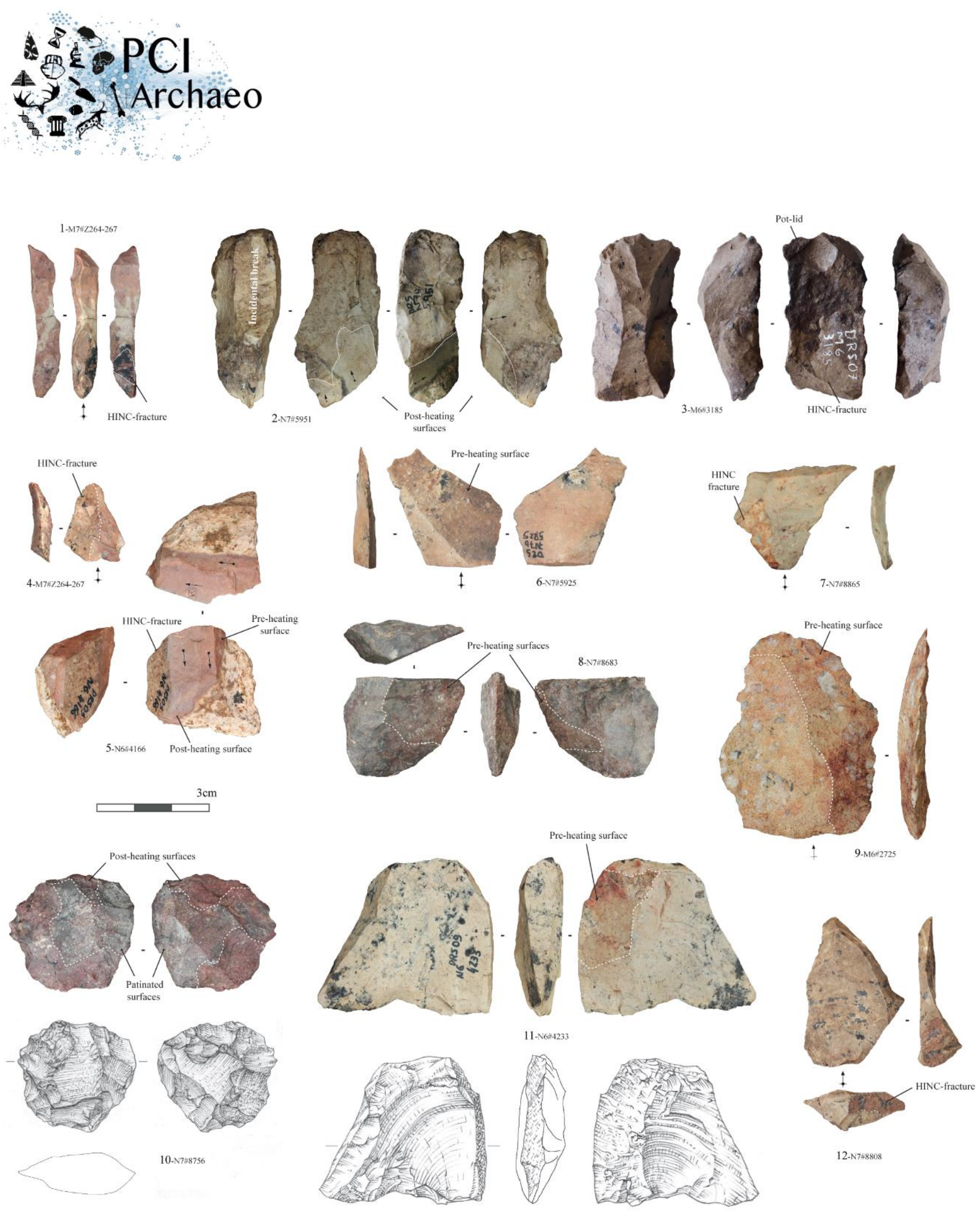

Figure 6. Heat-treated silcrete artefacts from the stratigraphic unit Lynn at Diepkloof Rock Shelter. $\mathrm{N}^{\circ} 1$ : crested bladelet (the black deposit overlapping the HINC-fracture is post-depositional). $\mathrm{N}^{\circ} 2$ : preformed bladelet core. $\mathrm{N}^{\circ} 3$, 5: bladelet cores. $\mathrm{N}^{\circ} 4,6,7$, 9: flakes. $\mathrm{N}^{\circ} 8,11$ : bipolar cores. $\mathrm{N}^{\circ} 10$ : Levallois core. $\mathrm{N}^{\circ} 12$ : Dos limité flake. All exotic silcrete except $\mathrm{n}^{\circ} 9$ (local silcrete). Notice that $n^{\circ} 3$ and 4 belong to one similar pinkish marbled yellow silcrete. (Drawings Michel Grenet). 
Table 2. Results of the analysis of the silcrete artifacts from the stratigraphic unit Lynn at Diepkloof Rock Shelter. Percentages under '\% total' refer to the total of analyzed artefacts in the stratigraphic unit, percentages under '\% det.' refer to all determinable artifacts in the given stratigraphic unit but exclude non-diagnostic artefacts. Percentages under '\% $\mathrm{HT}^{\prime}$ refer to the number of heat-treated artifacts in the stratigraphic unit.

\begin{tabular}{|c|c|c|c|c|}
\hline SU Lynn, total of analyzed artifacts: 465 & Count & $\%$ total & $\%$ det. & $\% \mathrm{HT}$ \\
\hline Indeterminate artifacts & 95 & $20 \%$ & & \\
\hline Not-heated artifacts & 32 & $6.9 \%$ & $8.6 \%$ & \\
\hline Artifacts with post-heating removal scars & 338 & $73 \%$ & $91 \%$ & \\
\hline \multicolumn{5}{|l|}{ Of which: } \\
\hline Artifacts with both pre- and post-heating removal scars & 58 & & & $17 \%$ \\
\hline Artifacts with HINC-fracture surfaces & 25 & & & $7.4 \%$ \\
\hline Artifacts with black tempering-residue & 3 & & & $0.9 \%$ \\
\hline
\end{tabular}

Heat treatment was predominantly applied to pieces of small size, or at least smaller pieces resulted from heat treatment, considering that the largest heated silcrete artifact recorded is ca. $60 \mathrm{~mm}$ long. Heat treatment occurred at different technological stages: (1) small blocks and flakes were heated before they were exploited as cores, with or without initial preparation (Fig. 6, $n^{\circ} 2$ and 3); (2) cores were heat-treated during the course of their exploitation (Fig. 6, ${ }^{\circ} 10$ ); and (3) flakes were heated prior to their retouch and/or shaping. At least one example (Fig. $6, n^{\circ} 9$ ) shows that heat treatment was also applied to local coarse-grained silcrete (this type of coarse-grained silcrete does often not produce unambiguous heating proxies, see: Schmidt et al., 2019).

\subsection{Lithic technology}

The lithic assemblage represents different chaînes opératoires that were partly adapted to the mechanical properties of the raw materials. We recognized seven distinct chaînes opératoires reflecting different objectives of the production and associated with different knowledge, skills and percussive techniques. Considering the limited size of the whole assemblage, we acknowledge that further studies will have to complete the present set of observations.

The flakes compose $51.8 \%$ of the lithic assemblage but laminar products such as bladelets are also well represented (Table 2). 
(1) A first chaîne opératoire is oriented towards the production of flakes following a centripetal reduction sequence that is reminiscent of a Levallois system. Various raw materials were selected such as quartzite, quartz and heat-treated silcrete. Flakes vary in morphologies including several specimens $(n=45)$ that present a limited back or dos limité (Fig. 6, $n^{\circ} 12$ ). Three cores have been found (Fig. 6, $n^{\circ} 10$ ).

(2) A second chaîne opératoire is directed towards the production of triangular flakes (dos limité excluded), documenting the exploitation of quartzite and heat-treated silcrete. Such morphology is represented by 33 specimens (ca. $6.5 \%$ of the flakes). Two main modalities are identified: one is similar to the accourcies points ( $n=11$ ) as described in Porraz et al. (2013a) (Fig. 7, $n^{\circ} 12$ ) while the other one suggests an intercalation within a series of unidirectional removals (Fig. 7, $n^{\circ} 11$ ). The triangular elements present the highest proportion of facetted platforms (42\%) in comparison with the rest of the industry (ca. $14 \%$ of facetted platforms). No core has been found.

(3) A third chaîne opératoire is oriented towards the production of flakes with quadrangular morphologies (Fig. $7, n^{\circ} 13,16$ ), in a close association with the exploitation of quartzite slabs. Flakes typically present an inclined butt and a distal cortical part (see for a geometric description of a similar nature: Schmid et al., 2016).

(4) A fourth chaîne opératoire aimed at the production of elongated blanks (ca. 10\% of the blanks have a length/width ratio between 1.5 and 2 ) and blades (ca. $2 \%$ have a length/width ratio $>2$ ) following a unidirectional reduction sequence (Fig. 7, $\mathrm{n}^{\circ} 10$ ). Quartzite and heat-treated silcrete are the two main raw materials that have been exploited following this reduction strategy. Little technological information is available except that blanks indicate the use of internal percussion with (hard) hammer stone. No core has been found.

(5) The fifth chaine opératoire is oriented towards the production of bladelets. This reduction sequence is strictly associated with heat-treated silcrete. In total, four bladelet cores and 36 bladelets have been identified in the assemblage (Fig. $6, n^{\circ} 2,3,5$, Fig. 7, n $\left.{ }^{\circ} 1-9\right)$. Bladelets generally present a plain platform (80\% out of 16 bladelets with an identifiable platform), they show occasional preparation of the overhang and percussive marks suggesting a tangential (soft) hammer stone percussion (Fig. 7, $n^{\circ} 7-9$ ). Bladelets have a mean length of $24.7 \mathrm{~mm}(\mathrm{std}=7$, med=22, $\mathrm{n}=10)$, a mean width of $8.2 \mathrm{~mm}$ ( $\mathrm{std}=1.7$, med=8.5, $\mathrm{n}=37$ ) and a mean thickness of $2 \mathrm{~mm}(\mathrm{std}=1$, $\operatorname{med}=2, \mathrm{n}=37$ ).

Of interest for the production of bladelets is a group of 31 products (including 21 products $\leq 20 \mathrm{~mm}$ ) that are petrographically similar (pinkish marbled yellow color), suggesting that they represent a single technological suite of operations. This group includes a refitting of five products (Fig. $7, n^{\circ} 1$ ) that shows the early stage of preparation of a bladelet core allowing the detachment of a crested bladelet to initiate the production. Within this raw material unit, one small flake exhibits the positive of a bulbar face indicating it was detached from a core-on-flake. On a total of 31 artefacts, only eight bladelets are present (including one crested bladelet, one hinged bladelet and two fragments) while the core is missing, suggesting a short in situ knapping event and the off-site transport of the core and the desired end-products (corresponding to phantom-core, Bamforth, 1990; Porraz, 2009). 

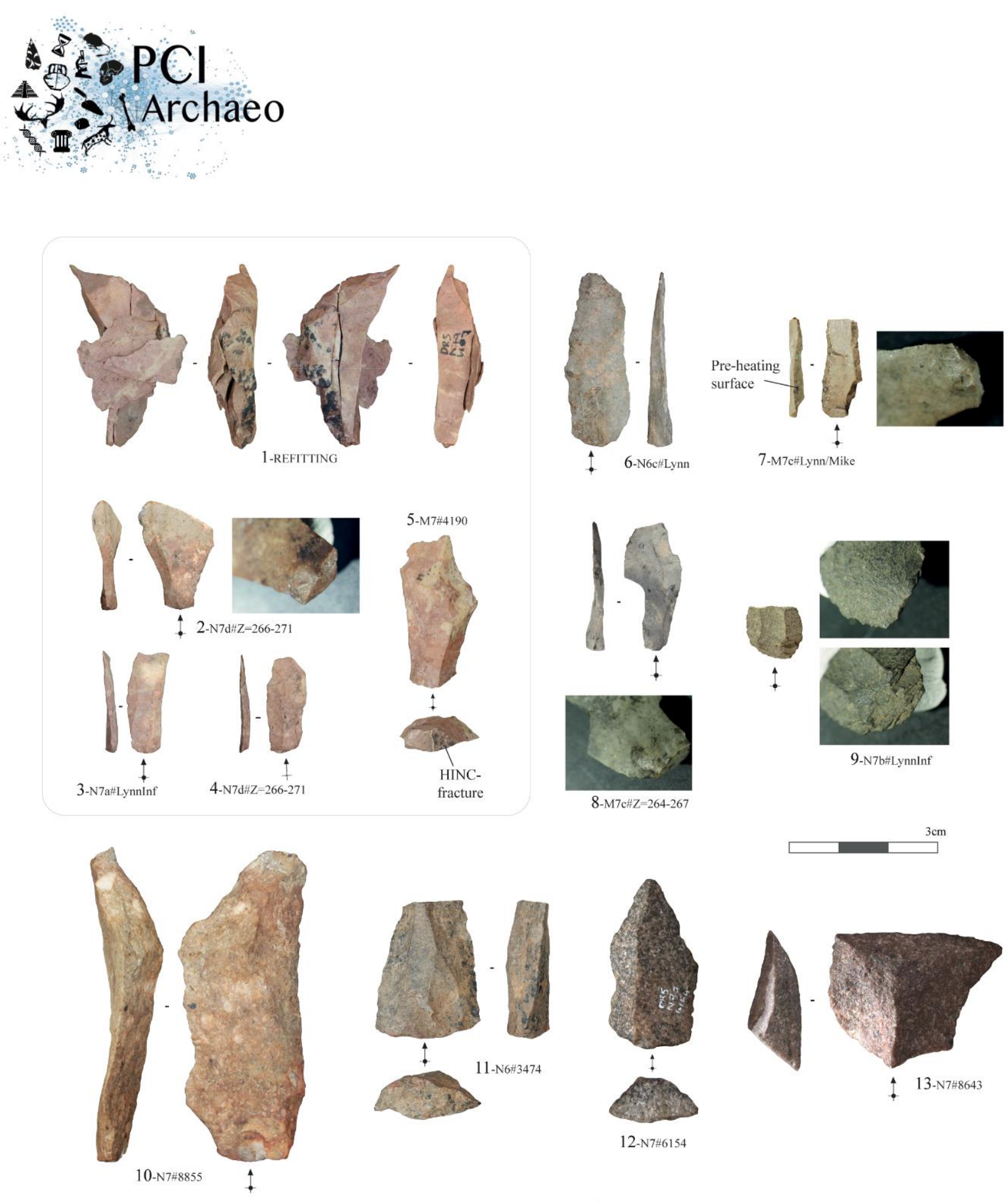

8-M7 $\mathrm{cHZ}=264-267$
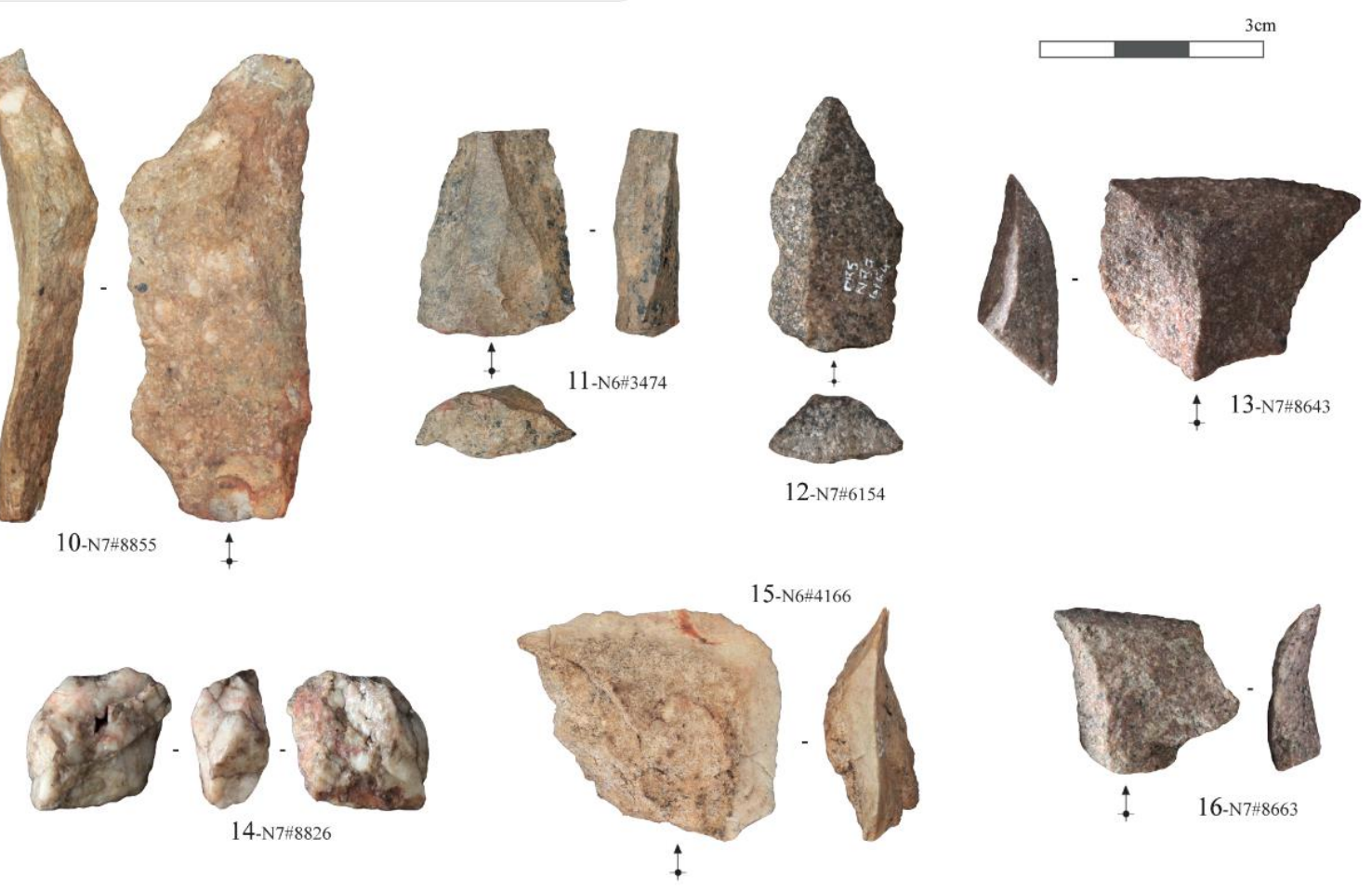

Figure 7. Blanks from the stratigraphic unit Lynn at Diepkloof Rock Shelter. $\mathrm{N}^{\circ} 1$ : refitting showing the preparation and the extraction of a crested bladelet (see also: Fig. $3, \mathrm{n}^{\circ} 1$ ) and the under-crested bladelet. $\mathrm{N}^{\circ} 2-9$ : bladelets. $\mathrm{N}^{\circ} 10$ : blades. $\mathrm{N}^{\circ} 11,12$ : triangular flakes. $\mathrm{N}^{\circ} 13,16$ : quadrangular flakes. $\mathrm{N}^{\circ} 14$ : bipolar core. $\mathrm{N}^{\circ} 15$ : cortical flakes. Exotic silcrete except $n^{\circ} 10$ (local silcrete), $n^{\circ} 12-13$ (quartzite) and $n^{\circ} 14$ (quartz). Notice that $n^{\circ} 1-9$ represent a pinkish marbled yellow silcrete as noticed in Figure 3. 
Technologically, the geometry of the refitting fits with one chunk of heat-treated silcrete that preserves an initial stage of crest preparation before being discarded, likely because of fragmentation (Fig. $6, n^{\circ} 2$ ). The three other bladelet cores document two additional geometric configurations. The first configuration (Fig. 6, $n^{\circ} 5$ ) is illustrated by a small heated silcrete block that documents the exploitation of two successive and independent surfaces by unidirectional removals while the second configuration (Fig. $6, n^{\circ} 3$ ) shows a bidirectional exploitation on an upper surface of a heated chunk that mirrors the volume of a flake.

(6) A sixth chaîne opératoire is based on the use of bipolar-on-anvil percussion. Some of the bipolar blanks show bidirectional and bifacial removals with filiform platforms (Fig. 7, $\mathrm{n}^{\circ} 14$ ) and are alternatively classified as pièces esquillées (cf. infra) (see: Barham, 1987; Le Brun-Ricalens, 2006; de la Penã, 2015). Thirty seven typical flakes attesting bipolar-on-anvil percussion are recorded and 30 of them are made on quartz, illustrating a close association between raw material selection and reduction strategy. A few examples show that bipolar-on-anvil percussion was occasionally applied to heat-treated silcrete as well (Fig. $\left.6, n^{\circ} 8,11\right)$.

(7) The final chaîne opératoire is oriented towards the production of bifacial pieces. In previous papers (Porraz et al., 2013a, 2014), we rejected the presence of bifacial pieces within SU Lynn and suggested a possible intrusion from the overlying SB units. However, subsequent excavations provided new data and confirmed the occurrence of bifacial artifacts (bifacial pieces and shaping flakes) within SU Lynn (Fig. 8). The assemblage is composed of 13 bifacial pieces and 39 shaping flakes. The bifacial pieces include a high number of unfinished forms, with a total of eight preforms that broke during initial shaping, and no complete finished specimen has been found. All raw materials were selected for bifacial shaping, although quartzite dominates the assemblage.

\subsection{Formal tools and functional macro- and micro-traces}

The lithic assemblage is composed of $7.8 \%$ of formal tools, a proportion that goes up to $16.5 \%$ when only non-local rocks are considered (Table 3). These tools are dominated by convergent forms that have been unifacially or bifacially shaped (Fig. 8-9). Unifacial points are exclusively associated with silcrete and other finegrained rocks; complete specimens $(n=11)$ have a maximum dimension that extends from 30 to $60 \mathrm{~mm}$ length, and only one example has a maximum thickness exceeding $10 \mathrm{~mm}$. 


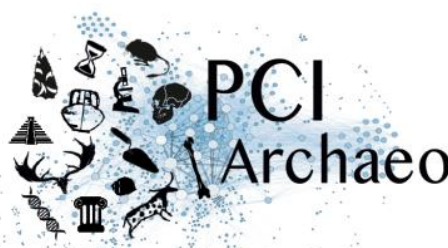

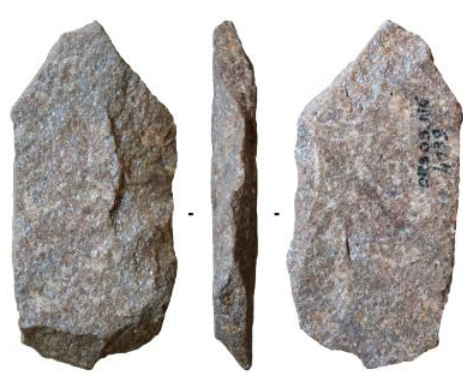

1-N6+4139

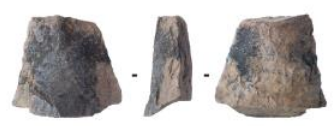

3. 6 6:4142

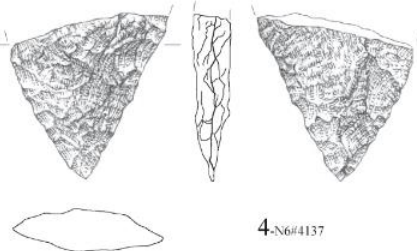

M6/7
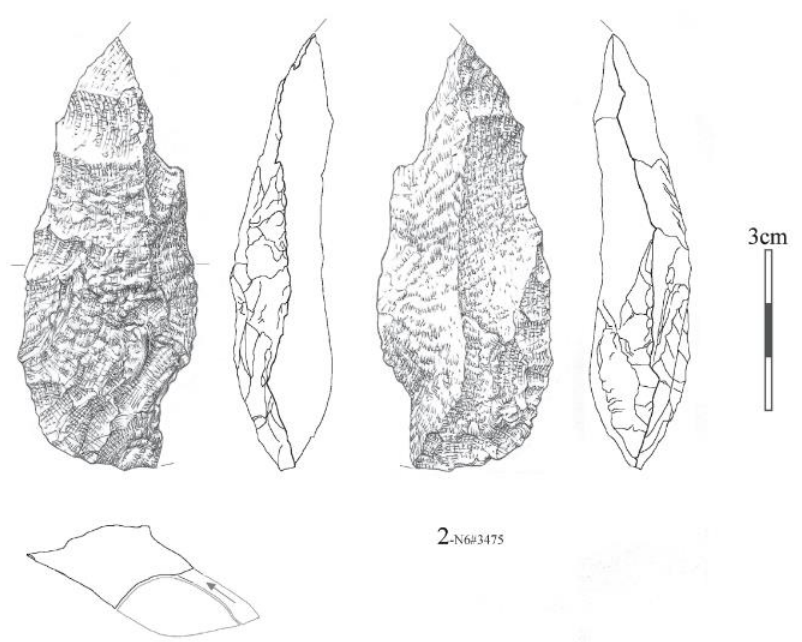

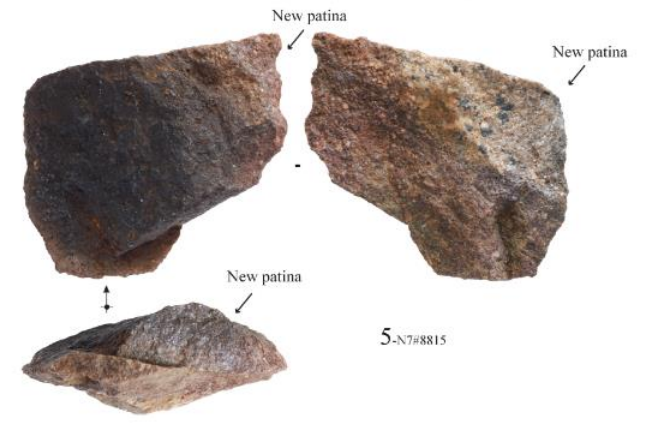

$\mathrm{N} 6 / 7$

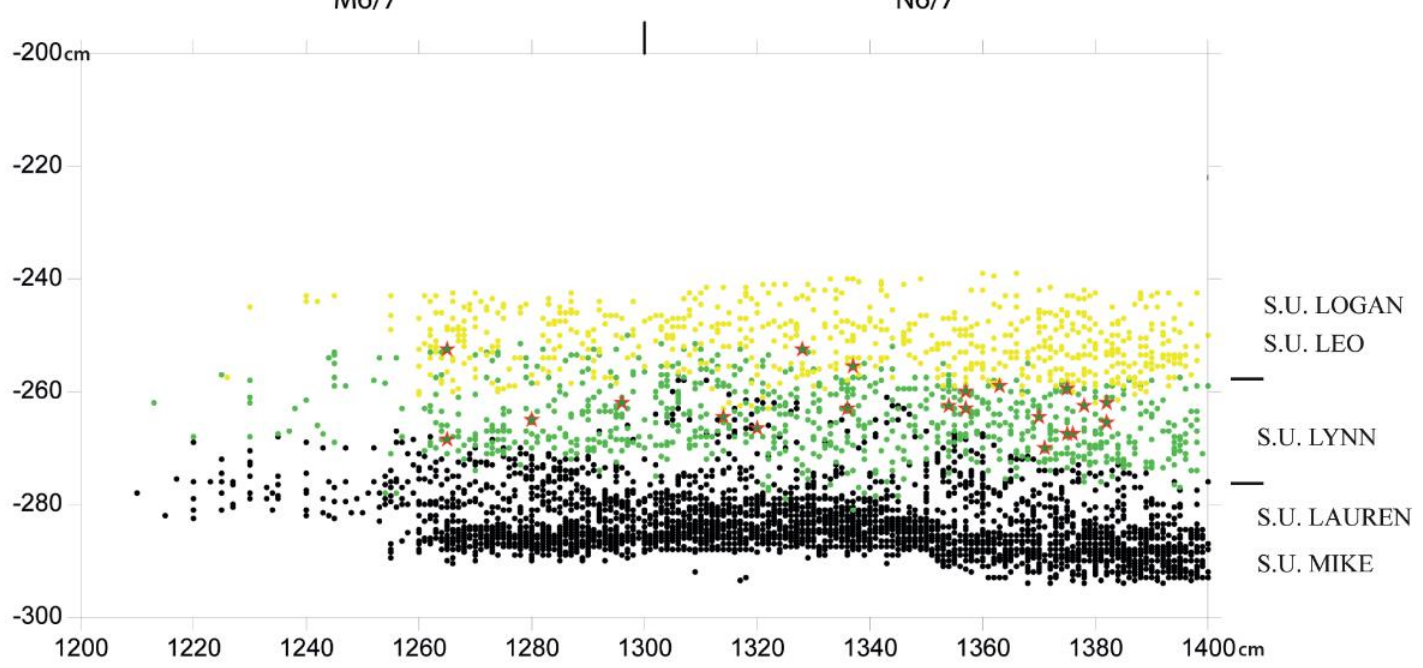

Figure 8. Bifacial pieces (all made on quartzite, except $n^{\circ} 3$ made on exotic silcrete) and stratigraphic distribution of all recorded bifacial implements (represented by stars) from the stratigraphic unit Lynn (Diepkloof Rock Shelter). $N^{\circ} 1$ : bifacial piece shaped on a quartzite slab and broken at an early stage of the manufacture. $\mathrm{N}^{\circ} 2$ : bifacial piece broken during manufacture. $\mathrm{N}^{\circ} 3$ : mesial fragment of a bifacial piece. $\mathrm{N}^{\circ} 4$ : proximal fragment of a bifacial piece. $\mathrm{N}^{\circ} 5$ : initial shaping of a quartzite flake broken at an early stage of the manufacture; the contrast between the removals and the surface of the flakes suggests the quartzite might have been (intentionally?) heated before shaping. 
Table 3. Typological list of retouched pieces from the stratigraphic unit Lynn (Diepkloof Rock Shelter) (*at different stages of manufacture).

\begin{tabular}{|l|cccccccc|}
\hline & Quartzite & Quartz & Local Silcrete & Exotic Silcrete & Hornfels & Others & TOTAL (N) & TOTAL (\%) \\
\hline Lateral scrapers & 2 & 2 & 2 & 5 & 0 & 0 & 11 & 15.3 \\
End-scrapers & 0 & 0 & 0 & 1 & 0 & 0 & 1 & 1.4 \\
Unifacial points & 0 & 0 & 5 & 13 & 0 & 1 & 19 & 26.4 \\
Bifacial points* & 8 & 1 & 0 & 3 & 0 & 1 & 13 & 18 \\
Denticulates & 5 & 1 & 0 & 0 & 0 & 0 & 6 & 8.3 \\
Notches & 1 & 1 & 0 & 0 & 0 & 0 & 2 & 2.8 \\
Pièces esquillées & 2 & 3 & 1 & 2 & 1 & 0 & 9 & 12.5 \\
Backed piece & 0 & 0 & 0 & 0 & 1 & 0 & 1 & 1.4 \\
Macro-tools & 2 & 0 & 0 & 0 & 0 & 0 & 2 & 2.8 \\
Fragments/marginal retouch & 3 & 0 & 1 & 4 & 0 & 0 & 8 & 11.1 \\
\hline TOTAL (N) & 23 & 8 & 9 & 28 & 2 & 2 & 72 & - \\
TOTAL (\%) & 31.9 & 11.1 & 12.5 & 38.9 & 2.8 & 2.8 & - & 100 \\
\hline
\end{tabular}

Four unifacial points have been bifacially shaped at their base. On those examples, the ventral thinning represents a final stage of shaping and suggests it was intended to facilitate the handling of the tool. Yet, three pieces show the putative use of a hafting adhesive with imprints that are similar to those previously described at Diepkloof (Charrié-Duhaut et al., 2013; Igreja and Porraz, 2013). One retouched triangular flake presents a black imprint covering its base on both the ventral and dorsal surfaces (Fig. 10, $n^{\circ} 3$ ): the outline of the imprint is clearly delimited and the black deposit is homogeneous at a macroscopic scale. In comparison, postdepositional imprints recorded on stone artifacts from Lynn and others SUs are never bifacially symmetrical, are randomly located on the pieces and present an "arborescent" pattern possibly related to manganese deposition (e.g. Fig. 10, $n^{\circ} 7$ ). Another piece is a unifacial point with two thick spots of a brown homogeneous deposit that is preserved on its proximal ventral face, suggesting these are possible residues of a glue (Fig. 10, $n^{\circ} 1$ ). The third piece is a silcrete blade with a black shallow imprint (Fig. 10, $n^{\circ} 5$ ). None of these black residues have yet been chemically analyzed. Unlike the two pointed tools that suggest the hafting was axial (i.e. in the axis of the apex of the points), the silcrete blade indicates that the hafting was lateral (i.e. parallel to the length axis of the tool).

The unifacial points vary in terms of dimensions, morphologies and shaping strategies, indicating that they may represent different functional populations, different designs or different stages of discard. The bifacial shaping/thinning of the proximal could arguably have facilitated handling, but other morphologies have been designed too. A few unifacial points (Fig. 9, $n^{\circ} 1$, 2, 6; Fig. 10, ${ }^{\circ} 6$ ) present a slanted base with one side kept unmodified, generating a slight asymmetric and off-centered axis to the point. One unifacial point (Fig. 9, $\left.n^{\circ} 3\right)$ is reminiscent of Tongati tools described at Sibudu Cave (Conard et al., 2012). 


\section{PCI
s. PCl. Archaeo}
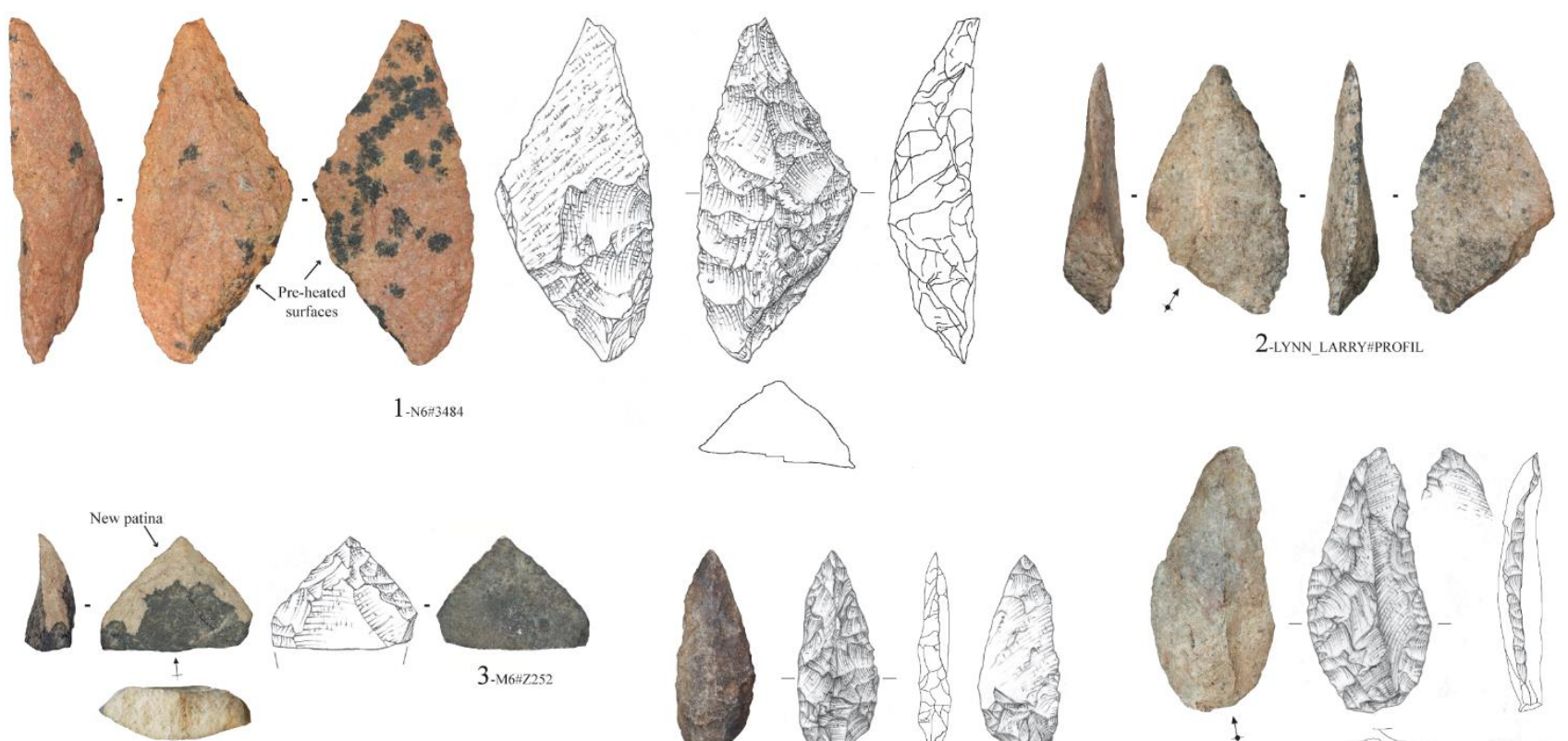

2-LYNN LARRYHPROFLL
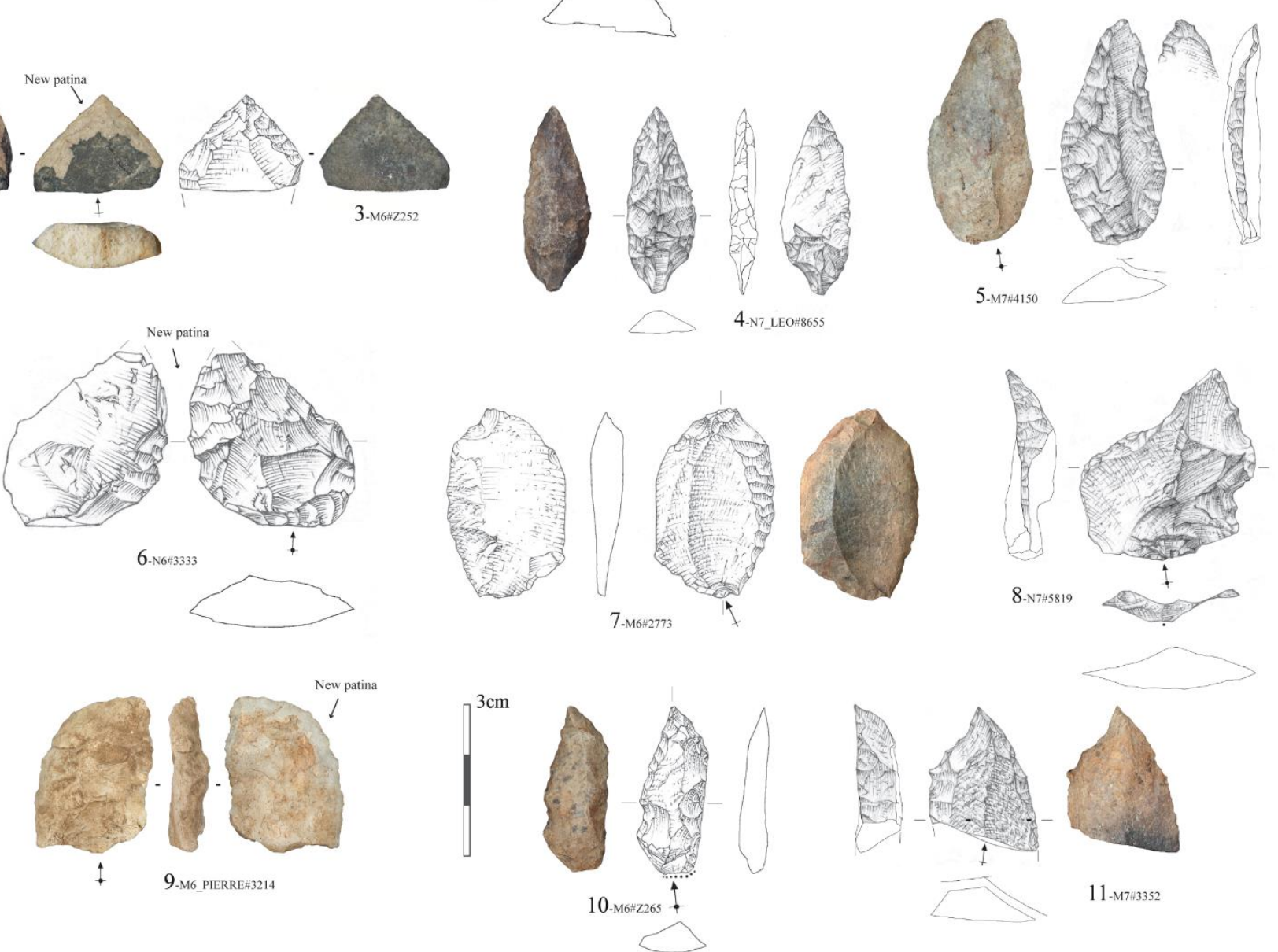

Figure 9. Formal tools from the stratigraphic unit Lynn at Diepkloof Rock Shelter. $\mathrm{N}^{\circ} 1$ : unifacial point shaped on a heattreated silcrete flake with bifacial proximal shaping. $\mathrm{N}^{\circ} 2,6$ : unifacial point. $\mathrm{N}^{\circ} 3$ : unifacial point of Tongati type; the retouch shows a recent patina. $N^{\circ} 4$ : unifacial point with bifacial proximal shaping. $N^{\circ} 5,7,8,10,11$ : unifacial points. $N^{\circ} 9$ : lateral scraper; the retouch shows a recent patina. All silcrete except $n^{\circ} 9$ : quartz. $\mathrm{N}^{\circ} 4$ has been discovered at the contact with the overlying stratigraphic unit Leo. (Drawings Michel Grenet). 

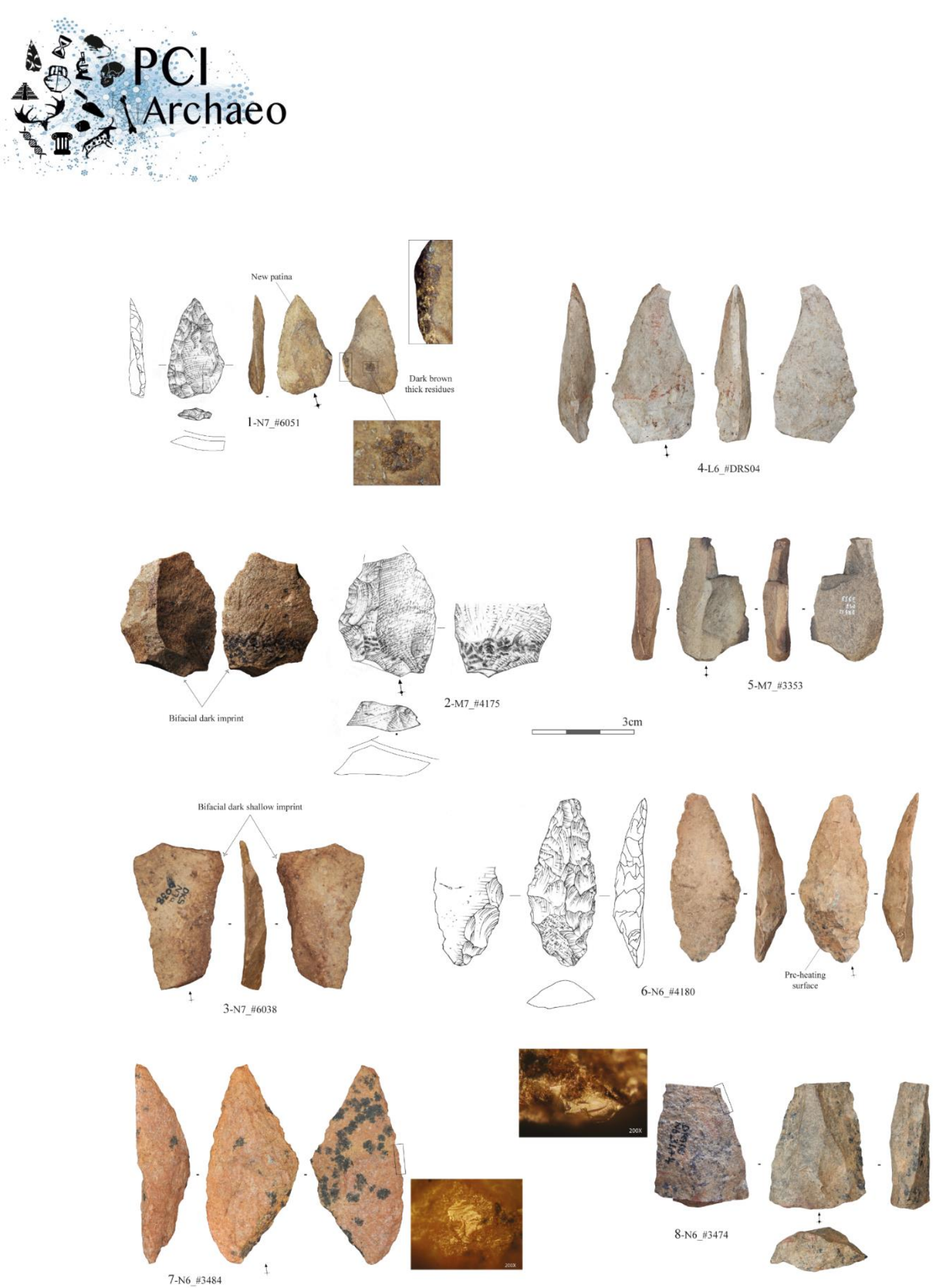

Figure 10. Lithics from the stratigraphic unit Lynn at Diepkloof Rock Shelter with details on functional traces. $\mathrm{N}^{\circ} 1$ : unifacial point with macro-residues on its proximal/ventral surface and interpreted as possible adhesive; the retouch shows a recent patina. $\mathrm{N}^{\circ} 2$ : unifacial point with step terminating removals and pseudo-burination; the chronology of the removals indicates the fracture predates the retouch. $\mathrm{N}^{\circ} 3$ : unifacial point with a bifacial black imprint on its proximal part that is interpreted as possible adhesive. $\mathrm{N}^{\circ} 4$ : triangular flake with a bending initiated and step terminating fracture (additional example from square L6). $\mathrm{N}^{\circ} 5$ : blade with a lateral bifacial shallow imprint that is interpreted as possible adhesive. $\mathrm{N}^{\circ} 6$ : unifacial point with a bifacial proximal shaping and with a bending initiated step terminating removal on the dorsal surface. $\mathrm{N}^{\circ} 7$ : unifacial point with a bifacial proximal shaping and a polish related to wood cutting. The tool is crushed at its tip. $\mathrm{N}^{\circ} 8$ : triangular flake with a straight fracture and a polish related to wood cutting. (Drawings M. Grenet). 
Fifty-six retouched pieces and blanks from SU Lynn were selected for macro- and microscopic use-wear analyses, following a methodology described in Igreja and Porraz (2013). The first screening of the collection led to sub-sampling 27 pieces ( $48 \%$ of the total sample), that preserved surfaces that were suitable for the functional analysis. The results of the study identify 13 pieces with functionally diagnostic micro- and/or macrotraces (Table 4). Importantly, six pieces (three unifacial points, one triangular flake, one laminar flake and one flake) exhibit distal fractures such as pseudo-burination and step terminating removals (Fig. 10) that result from an impact and that may relate to the use as projectile. However, triangular tools encompassed a broader functional perspective: one unifacial point and one triangular flake show bright and smooth polishes on the microtopography of the lateral edges that are characteristic of a longitudinal use (Fig. 10, $n^{\circ} 7,8$ ). One of the pièces esquillées (Fig. $6, \mathrm{n}^{\circ} 8$ ), alternatively classified as bipolar cores, presents a polish typical of a contact with a hard organic material such as wood. None of the bifacial fragments has been analyzed yet.

Table 4. Synthesis of the analyzed material from the stratigraphic unit Lynn at Diepkloof Rock Shelter and results of the functional analysis (the N.U. Zones correspond to the number of used zones; long. = longitudinal).

\begin{tabular}{|l|ccccccccc|}
\hline & \multicolumn{3}{|c}{ State of preservation } & & \multicolumn{7}{c}{ Worked material and motions } \\
& Total & good & weathered & $\begin{array}{c}\text { with } \\
\text { usewear }\end{array}$ & $\begin{array}{c}\text { N.U. } \\
\text { Zones }\end{array}$ & $\begin{array}{c}\text { wood } \\
\text { long. }\end{array}$ & $\begin{array}{c}\text { hard } \\
\text { long. }\end{array}$ & $\begin{array}{c}\text { Impact } \\
\text { fracture }\end{array}$ & $\begin{array}{c}\text { TOTAL } \\
\text { (N) }\end{array}$ \\
\hline Unifacial points & 12 & 6 & 6 & 4 & 5 & 1 & 1 & 3 & 5 \\
Triangular flakes & 7 & 3 & 4 & 3 & 3 & 2 & 0 & 1 & 3 \\
Flakes & 24 & 16 & 8 & 1 & 1 & 0 & 0 & 1 & 1 \\
Laminar flakes & 5 & 0 & 5 & 1 & 1 & 0 & 0 & 1 & 1 \\
Blades & 3 & 1 & 2 & 1 & 1 & 0 & 1 & 0 & 1 \\
Bladelets & 1 & 0 & 1 & 0 & 0 & 0 & 0 & 0 & 0 \\
Pièces esquillées & 3 & 1 & 2 & 1 & 1 & 1 & 0 & 0 & 1 \\
Lateral scrapers & 1 & 0 & 1 & 0 & 0 & 0 & 0 & 0 & 0 \\
\hline Total (N) & 56 & 27 & 29 & 11 & 12 & 4 & 12 & 6 & 12 \\
\hline
\end{tabular}

\subsection{Raw material provisioning strategies and mobility}

The lithic assemblage of SU Lynn illustrates a raw material provisioning strategy primarily based on local availability. However, exotic rocks introduced from distances greater than $20 \mathrm{~km}$ comprise $21 \%$ of the lithic assemblage (Table 2). In comparison with preceding occupations of the shelter (MSA Mike) where only $2 \%$ of non-local rocks were recorded, SU Lynn points towards a shift in lithic procurement strategies in contrast to the previous layers, and initiates a trend in terms of rock selection and territorial organization. This trend is associated with the exploitation of silcrete and persists throughout the following SB and HP occupations (Porraz et al., 2013a, 2014). 


\section{sapper}

The study demonstrates that the Diepkloof inhabitants applied different reduction sequences in accordance with different objectives and in concordance with the diversity of the raw materials. People often modified the blanks with a proportion of $7.8 \%$ of formal tools that rises to $16.3 \%$ when only silcrete is considered (Table 3 ), suggesting that shaping or retouching was a solution to adjust morphologies to a variety of blanks. The typological corpus is composed of various tool types that illustrate different functional designs but also distinct degrees of tool consumption. The hypothesis of frequent re-tooling is supported by examples of retouched pieces with double-patina (see: Fig. $9, n^{\circ} 3,9$, Fig. 10, $n^{\circ} 1$ ), indicating that the tools were discarded before being re-used.

The exotic rocks were introduced to the site in different forms, such as small blocks, cores, blanks and tools. This technological diversity together with the petrographic variability indicates the lithic assemblage represents several episodes of introduction, export (?) and discard. The results of our study suggest that short knapping activities took place in situ, supporting the hypothesis of exotic items that were carried by groups from one place to the next (Kuhn, 1995; Porraz, 2009). Such form of raw material procurement strategy is indicative of people who were coping with their technological needs by following individual provisioning strategies (Kuhn, 1995), in tune with the hypothesis that Diepkloof was inhabited in the framework of "shortterm" occupations (Miller et al., 2013; Porraz et al., 2014).

Unlike the following SB and HP occupations, the pre-SB Lynn represents one single stratigraphic unit, suggesting this might have been a relatively short-lived technology. This hypothesis finds a general echo when considering the data published in the literature since the pre-SB Lynn has very few technological and typological equivalents. We may mention the presence of unifacial and bifacial points at the end of the MSA $2 \mathrm{~b}$ as noticed by Volman (1984) and we may call to mind changes that occurred at the end of the MSA II at Klasies River (Singer and Wymer, 1982; Wurz, 2000). Regardless, these data remain too preliminary to formulate any concluding remarks. The fact that the pre-SB Lynn would be characterized by a "low archaeological visibility" is supported at Diepkloof by the taphonomic results that highlight a substantial contribution by large raptors and other nonhuman agents (Steele and Klein, 2013), consistent with shorter term and discontinuous human occupations at the site.

The data described for the pre-SB Lynn recognize groups that were moving over long distances $(>20 \mathrm{~km})$, taking the benefit of local raw material availability but carrying items from site to site to cope with unforeseen circumstances. In comparison with preceding occupations, the pre-SB Lynn introduces a techno-economic change, which might be the result of populations that had to face and adapt to new conditions, either climatic, demographic and/or socio-economic. On that regard, botanical (Cartwright, 2013) and faunal (Steele and Klein, 2013) studies provide useful information yet limited by the sample size.

\section{Implications}

\subsection{Heating silcrète}

Heat treatment is documented in the SB at Hollow Rock Shelter (Schmidt and Högberg, 2018) and Blombos Cave (Mourre et al., 2010), in a HP-like context at Pinnacle Point 5/6 (Brown et al., 2009), in the HP at Diepkloof (Porraz et al., 2013a; Schmidt et al., 2015) and Klipdrift Shelter (Delagnes et al., 2016) and in the HP and post- 


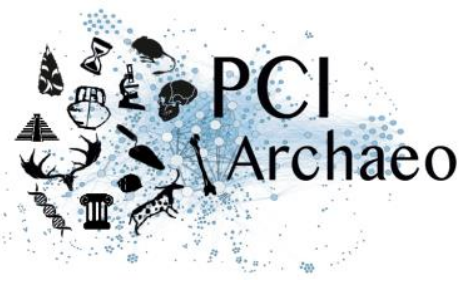

HP at Mertenhof Rock Shelter (Schmidt and Mackay, 2016), thus documenting a technology that was widely applied by populations from the Western Cape silcrete belt from the second part of MIS5 to the beginning of MIS4. The chronological development of this technology still requires further clarification but, so far, most recent archaeological evidence also documents it in MIS2, namely in the Robberg of Elands Bay Cave (Porraz et al., 2016). Regarding the earliest expressions of silcrete heat treatment, Brown et al. (2009) proposed that the technology may be as old as 164 ka at Pinnacle Point 5/6, but the published data do not appear to fully support this hypothesis. The earliest unambiguous cases of silcrete heat treatment are documented at Hoedjiespunt (Schmidt et al., 2020) and date back to MIS5e.

At Diepkloof, the earliest evidence of silcrete heat treatment appears with the pre-SB Lynn, which coincides with a substantial increase in the number of silcrete pieces (from $1 \%$ of the raw material spectrum during MSA Mike to $24.7 \%$ during the pre-SB Lynn). The high number of silcrete artefacts with diagnostic heating features (up to $91 \%$, Table 3 ) indicates that heat treatment was systematically and intentionally applied to silcrete. The assemblage shows that small blocks and flakes were heat-treated before or during their exploitation as cores or the shaping into tools (Fig. 9, $n^{\circ} 1$ ). Silcrete heat treatment was applied at different stages of the reduction sequence and for various purposes. Whether silcrete could have been heat-treated several times is uncertain but one core may support such a hypothesis (Fig. 6, $n^{\circ} 10$ ).

Silcrete heat treatment offers several technological benefits. New bonds between quartz crystals and at defect sites are created (Schmidt et al., 2017). This leads to several transformations of the rocks' fracture behavior, including reduced fracture toughness (Domanski et al., 1992; Schmidt et al., 2019) and increasing Weibull modulus (Schmidt et al., 2019). The consequences for knapping are that in heat-treated silcrete, fractures propagate with less energy and flake detachments are more expectable because the range of forces required to initiate the fracture is reduced. Consequently, the material is more predictable, which allows the knappers to have a better accuracy and control during their operations, enhancing its success in producing thin end-products (Pargeter and Schmidt, 2020). As such, heat treatment can be regarded as a pre-condition for technological operations such as shaping bifacial pieces with pressure-flaking or producing bladelets with soft hammer percussion, but it is less critical for retouching flakes with direct percussion or exploiting cores with bipolar percussion.

Due to its overall low water content, silcrete can be heated with faster heating rates than flint. This has initially triggered the hypothesis of above-ground silcrete heat treatment in open fires (Schmidt et al., 2013; for an alternative hypothesis see: Wadley and Prinsloo, 2014) that was later confirmed at Diepkloof (Schmidt et al., 2015). During the pre-SB Lynn, lithic procurement was based on personal gears implying the discard of pieces that were sometimes re-used later in time. Such practice has been noticed in several Middle Palaeolithic (e.g. Gravina and Discamps, 2015; Turq et al., 2013) and MSA sites (Porraz et al., 2018), falling into the category of "scavenging tools" (Bamforth, 1990). Scavenged artifacts are identifiable when the initial blank developed an alteration of its surface (a patina), due to for example chemical dissolution, coloring or heat exposure. Following that line of argumentation, the contrast between a pre-heating and post-heating surface may in principle also illustrate some "scavenging economies". This is the case at the Middle Palaeolithic sites of Pié Lombard (Porraz, 2005) and Vallabrix (Meignen, 1982), but also at the Upper Palaeolithic site of the Moli del Salt (Vaquero et al. 2012), where flint artefacts were unintentionally heated, picked up again and modified, creating a "thermal double patina" effect. 


\section{sher}

With regard to the apparent simplicity of silcrete heat treatment, the numerous lines of evidence of fire use and the overall number of "scavenged tools", the null hypothesis is that the discovery of heat treatment may have occurred fortuitously. Discarded silcrete artifacts may have been heated incidentally in or near domestic or natural fires, then picked up a few days, months or years later. Experienced knappers would have noticed the changes of flaking properties, tested, experimented with and reiterated the heating operation using small blocks and flakes. Following that scenario, heat treatment may have been discovered independently in different places and at different times, and we might expect a discontinuous archaeological record of heat treatment proxies varying with the raw material provisioning strategies (selection of silcrete or not).

Pieces with double patina are made from silcrete (Fig. 9, $n^{\circ} 3$, Fig. 10, $n^{\circ} 1$ ) but also quartz (n=1, Fig. 9, $n^{\circ} 9$ ) and quartzite $(n=3)$. One example of a quartzite piece is a flake discarded at an early stage of shaping, with an unusual black imprint on its dorsal surface, perhaps soot, and with removals showing a new and fresher looking aspect that suggests the flake was in contact with a fire before being shaped into a bifacial piece (Fig. $8, n^{\circ} 5$ ). Yet, considering the nature of the raw material, no benefit is expected from heat treatment of most quartzites (quartzite is a metamorphic rock that was already exposed to heat during its formation history, see for example: Kornprobst, 2002), suggesting either the associated shaping/heating was incidental, or the process was not yet fully grasped by the operators. Similarly, these pieces also include a diminutive centripetal silcrete core that has seemingly been re-heated during exploitation (Fig. 6, $n^{\circ} 10$ ). Such behavior may lead us to question the knapper's understanding of the underlying processes, as reheating is unlikely to procure a supplementary advantage. Future chemical and structural analyses of this piece should allow further investigation of this hypothesis. The "discard-recycling" hypothesis contrasts with previously proposed hypotheses on heat-fracturing (Porraz et al., 2016; Schmidt et al., 2020). According to this hypothesis, the improvement of knapping quality by heat treatment may, at least in the first phase following its discovery, have been a by-product of another behavior: fracturing rocks with fire prior to knapping.

The technological gain after altering silcrete by heat treatment is tremendous, leading to the transformation of the natural rock into a new raw material with different properties. In the sequence of Diepkloof, there is a clear correlation between heat treatment and silcrete exploitation, suggesting that heating was pivotal for later technological developments. During the pre-SB Lynn, heat treatment occurred at various steps and was embedded in various technologies: to produce bladelets, to shape scrapers and to produce blanks by bipolar percussion. Heat treatment was widely applied regardless of the technological sophistication of the reduction sequences. This set of observations suggests that heat treatment documents a stage of development at Diepkloof, where operators were still experimenting with the outcomes of the innovation.

\subsection{Experimenting with new tools and new reduction strategies}

The pre-SB Lynn marks the beginning of new raw material procurement strategies at Diepkloof. This change reflects not only a transformation in the territorial organization of human groups, but it also indicates a change in the raw material selection strategy (Tomasso and Porraz, 2016) with a selection oriented towards finergrained varieties. In close association with silcrete, we notice the production of bladelets. The reduction sequence was well-controlled, seemingly favoring the exploitation of cores-on-flakes, shaping the volume by 


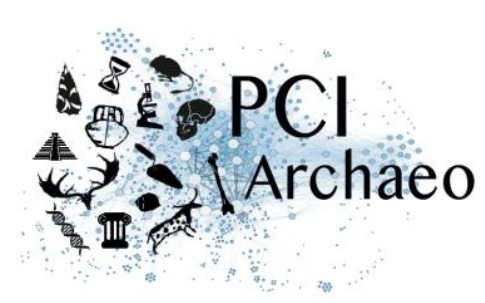

the preparation of a crest and applying a marginal direct percussion with a soft hammer(stone) to extract the blanks. None of the bladelets was retouched and no functional traces have been identified.

Bladelets signal a trend towards tool normalization and miniaturization and carry implications with regard to the emergence of the first composite technologies. The earliest evidence of bladelet production in southern Africa is presently documented at Pinnacle Point 13B, in the layer Lower LC-MSA dated to ca. $160 \pm 10 \mathrm{ka}$ BP (Marean et al., 2007). The continuous distribution of width from blades to bladelets indicates that bladelet production may result from the diminution of large volumes into smaller ones. The bladelets show rare preparation of the platform and none of them have been retouched. At Pinnacle Point 13B, the bladelet production disappears in the overlying layers and reappears only later in time with the HP (Brown et al., 2012; Porraz et al., 2013a). At Diepkloof, the HP technology is based on the exploitation of heat-treated silcrete and the use of soft hammer stone percussion.

The pre-SB Lynn characterizes a technology based on a regular shaping of formal tools. Amongst the set of formal tools, points are the dominant forms, being represented by unifacial points, unifacial points with partial bifacial thinning and bifacial points. There is no evidence supporting a technological continuum from one type to another, which suggests the three types formed distinct alternatives of production. In the sequence of Diepkloof, bifacial technology occurs first during the pre-SB Lynn, but only developed during the SB.

The ventral shaping observed on some of the unifacial points suggests the modification was intended to facilitate the handling or hafting of the tools. This interpretation is additionally supported by a few pieces with a black imprint, not yet chemically studied, suggesting that adhesive was routinely used by pre-SB groups. The hafting of points may have been part of broader functional innovations such as their use as projectiles, as documented in the MIS5 pre-SB from Sibudu Cave (Rots et al., 2017) and as suggested by some apical fractures from the pre-SB Lynn.

The pre-SB Lynn assemblage illustrates the coexistence of seven chaînes opératoires that composed the technological repertoire of the populations. Those chaînes opératoires varied in accordance with the functional objectives and the raw materials, employing various skills and percussive techniques. Similarly, various shaping strategies were at work, providing further evidence for the technological and functional flexibility of the Diepkloof inhabitants. This flexibility was expressed in a context when people experienced a change in their territorial and socio-economical organization, suggesting people faced new environmental or socioeconomical circumstances and had to adapt their behaviors.

\subsection{Emerging symbols}

Abstract depictions apply to different mediums, such as ochre, bones, ostrich eggshells, shells, rock walls and stones, not to mention other perishable raw materials. These media all differ; they are functional or not, fragile or robust, soft or hard, organic or mineral, rare or common, intimate or collective. We believe the initial step to approaching the meaning of an abstract depiction is first to understand what could be the technical role and social significance of the medium by itself. At Diepkloof, the engraved piece has been found with other faunal remains and it displays no apparently significant spatial distribution. The engraved bone might represent one object of waste amongst others, though it is worth noticing that the size of the bone falls within the largest animal prey hunted by the Diepkloof inhabitants. 


\section{sapper}

Engravings occur at two different times in the sequence of Diepkloof, taking two different forms. During the HP, engravings were made on ostrich eggshell containers, which represent collective and functional items. Engravings were carved according to a narrow set of geometric rules that were shared over a large territory (Henshilwood et al., 2014; Texier et al., 2013). On the contrary, during the pre-SB Lynn, only one engraving has been found, carved on what can be considered to be a waste product; though the hypothesis that the fragmented bone was a functional object cannot be rejected.

The engraved bone from the pre-SB Lynn coincides chronologically with the oldest engraved ochre pieces from Blombos Cave and Klasies River, but differs from other more recent engraved bones from southern Africa where parallel and perpendicular incisions dominate (d'Errico and Henshilwood, 2007; d'Errico et al., 2001; 2012a, 2012b; Henshiwood et al., 2009). The engraved bone also radically differs from the numerous geometric designs engraved on ostrich eggshells in the HP of Diepkloof. In SU Lynn, the engraving consists of the association of straight lines organized in a rhomboid pattern, a design that notably recalls the pattern of two engraved ochre pieces from the SB of Blombos Cave (Henshilwood et al., 2009) as well as one engraved piece from the HP/post-HP of Klein Kliphuis (Mackay and Welz, 2008). The reasons behind this resemblance can be interpreted from different perspectives (see: Anderson, 2012; Hodgson, 2006; Mellet et al., 2019a; 2019b). Regardless of the underlying cognitive mechanisms behind their production and usage, the similarities in forms between the engravings from the pre-SB of Diepkloof and the SB of Blombos Cave support the hypothesis that early engravings illustrate a pioneer stage of symbolic graphic design amongst these populations. Later graphic developments in the HP of Diepkloof (Texier et al, 2010; 2013) and Klipdrift Shelter (Henshilwood et al., 2014) show the production of geometric engravings but with an abundance and a stylistic variety that differ substantially, suggesting a significant change in the way the geometric designs were envisioned and manipulated.

The use of ochre and its transformation by grinding also fuel the question of the range of materials and symbols that were manipulated by pre-SB inhabitants. The preferential selection of fine-grained iron rich materials as well as the absence of red residues on lithic artefacts is not in favor of the functional use of ochre as a loading agent (Wadley et al. 2004). The ochre spectrum at Diepkloof supports its use as pigments, although no direct evidence supports the assumption that ochre powder was embedded with symbolic meanings (see: Dayet et al. 2013). The tradition of grinding iron-rich ochre materials at Diepkloof persists without discontinuity from the pre-SB Lynn to the post-HP but it remains unknown when ochre started to be used to convey symbolic messages. Ochre could have carried a symbolic meaning since its very first use, or the embodiment of symbolic messages through ochre exapted from one or several pioneering functional uses.

Symbols transform and sublimate communication within and between groups of people and proceed as external memories. A symbol represents coded information that is stored and shared within a group, contributing to the establishment and maintenance of social conventions and beliefs (see: Henshilwood and $d^{\prime}$ Errico, 2011). The engraved bone from the pre-SB Lynn promotes an individual act with a social and cultural impact that stayed seemingly confined and intimate. Only later in time at Diepkloof, during the HP, did populations manipulate graphic symbols with a visible and collective meaning. The pre-SB Lynn stands out as one of the first geometric designs so far recorded in the southern African MSA. We argue that the social perception of graphic representations changed from the pre-SB to the HP and that the pre-SB Lynn records a stage where graphic symbols were just at the dawn of being established within the cultural repertoire of the population. 


\section{From experimentation to innovation in the MIS5 of southern Africa}

In a previous paper (Porraz et al., 2013b), we identified the HP as a major innovative phase within the chrono-cultural sequence of Diepkloof. We also supported a scenario of cultural changes that occurred continuously from the pre-SB to the post-HP, at different rhythms and under different circumstances. The new data coming from the excavation of the lower deposits help us to refine our model.

The pre-SB Lynn represents one SU that shows substantial changes in the way people were procuring their raw materials and manufacturing their equipment. For the first time in the sequence, we observe a set of innovative traits including the selection and transport of fine-grained rocks over distances greater than $20 \mathrm{~km}$, their deliberate alteration by heat treatment, the production of bladelets, the shaping of unifacial and bifacial points and the use of adhesive. Additionally, one abstract engraving was discovered. In other words, most of the behavioral novelties that later typify the SB and the HP already existed -in one form or another- at the time of the pre-SB Lynn.

The innovations characterizing the pre-SB Lynn find later expression in the following SB and HP, although they have been manipulated differently. Silcrete heat treatment during the SB was applied in association with the shaping of thin lanceolate bifacial pieces involving pressure flaking (Mourre et al., 2010; but also see: Schmidt and Högberg, 2018), while engravings on ostrich eggshells during the HP expressed a repetitive and codified pattern (Texier et al., 2013). In comparison, heat treatment during the pre-SB Lynn was applied in various technological sequences and the engraving was isolated and made on a raw material that may not have been "visible" to the whole group (nor to other groups). All discoveries likely provided immediate benefits to the groups. However, the new shapes that those discoveries took during the SB and the HP suggest that only later in time did heat treatment and abstract engravings provided their full cultural and technological advantages, supporting a process of improvement for the first innovation and a process of cultural exaptation for the second one.

The pre-SB Lynn points towards a shift in the territorial organization and the way groups were spatially structured. We suggest that a restructuring of territorial and socio-economic systems during the pre-SB Lynn led to a loss of social rules that had emphasized conformity. This loss may have in turn promoted individual learning (versus social learning, see: Cresswell, 1994; McElreath 2010, Roux, 2013) and favored experimentation as a cultural response to face new conditions. During the pre-SB Lynn, seven different lithic chaînes opératoires were concomitantly at work, including the manufacture of bifacial pieces and the production of bladelets. We argue that the socio-economical change promoted initiatives and favored experimentations as a cultural way toward innovation. Short term almost idiosyncratic responses would have become longer term "adaptive" implementations. Experimentations within and between groups contributed to aggregate new ideas that composed the cultural reservoir of the MIS5 populations.

The West Coast of South Africa and, by extension, the silcrete belt area, the Winter-rainfall Zone and the south western coast of South Africa benefit from unique geological and ecological conditions. The role of this region within the behavioral evolution of $\mathrm{AMHs}$ has been critical and the archaeological record of Diepkloof supports the hypothesis that many early innovative behaviors concentrate in this specific region of the world.

There are still many pieces missing in the MSA chrono-cultural puzzle of southern Africa, and the pre-SB Lynn adds a new piece. Diepkloof is certainly unique for the chronological window it provides and very few sites offer alternative examples, Sibudu Cave being one of them. The pre-SB at Sibudu also records the 


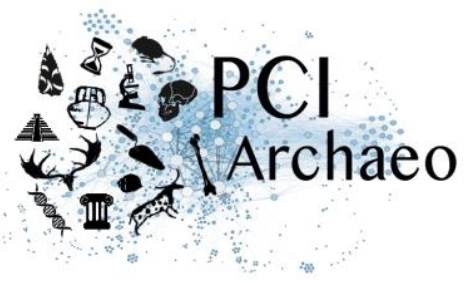

development of innovative technologies such as the use of pressure flaking to serrate projectiles (Rots et al., 2017), the production of blades (Schmid et al., 2019), and the manufacture of bone tools (d'Errico et al., 2012a). However, the technological traditions differ substantially from those recorded at Diepkloof (Schmid, 2019). Located some $1500 \mathrm{~km}$ east of Diepkloof and in a markedly different ecological setting, the pre-SB to SB sequence of Sibudu underlines distinct cultural trajectories between the KwaZulu-Natal Province and the Western Cape Province, i.e. between the Indian Ocean Coastal Belt and the Fynbos Biomes. Notwithstanding, both sites show early innovative behaviors at work.

The MIS5 in southern Africa marks a time and a place in human evolution when ideas and innovations flourished in rapid succession, one of those "seemingly fertile intervals" (Kuhn, 2012: 69). We do acknowledge that such historical discourse shall also promote a longer-term evolutionary perspective paying attention to earlier innovations. Ochre processing (Watts et al., 2016) and hafting technology (Wilkins et al. 2012, but see: Rots and Plisson, 2014) provide examples of early cultural changes, which enlarge the chronological frame in which we shall perceive the cultural evolution of AMHs societies. These early discoveries do not reduce the nature and importance of the set of behavioral changes recorded during the MIS5 in southern Africa, which marks a step in the way people were socially and economically organized.

The emergence of new behaviors in southern Africa was neither sudden, nor synchronous; it did not happen in a single place and it was not monolithic, taking as many forms as circumstances and human creativity prevailed. New behaviors multiplied during the MIS5 pre-SB and persisted until the SB and the HP (and later). The southern African MSA sites document that pre-SB societies experimented with new practices, which were eventually combined into a cultural repertoire (see: Henrich and McElreath, 2003) and that the SB and the HP only form the most visible part of a long evolutionary process. The notions of cultural exaptation and cultural neural reuse as promoted by d'Errico and Colagé (2008) provide a good conceptual background to the current archaeological record where discontinuity predominates. Elaborating on the principles of cultural transmission (see: Cavalli-Sforza and Feldman, 1981; Durham, 1991; Henrich, 2015; Mesoudi, 2016; Roux, 2010) to explain the punctuated nature of innovative behavioral proxies in southern Africa, we postulate a scenario where information percolated vertically -between generations- and horizontally -within and between groups. Vertical transmission proceeded in the form of direct oral transmission and/or external memorization through material culture, while horizontal transmission proceeded in the form of repeated contacts and exchanges within and between groups. Social interactions and material signs such as engravings and engraved artefacts, which are mnemonic in character, would have compensated the cultural discontinuities occurring locally in some places and/or during certain times. It is assumed that people from southern Africa during the MIS5, regardless of their technological and cultural differences, formed a pool of people socially and biologically connected to each other.

\section{Acknowledgements}

D \& M. van Wyk, J. Pollet for permission to work on their land, the Heritage Western Cape for permission to excavate at Diepkloof Rock Shelter and all students involved in the excavation every year since 1999. We would like to thank Dolores Jacobs and Louisa Hutten for their constant help, as well as Teresa Steele and Richard G. Klein for sharing their results on the faunal spectrum of SU Lynn. Financial support for PS was provided by the 
Deutsche Forschungsgemeinschaft (DFG-grant number SCHM 3275/2-1). The Diepkloof project is supported by the French Ministry of Foreign Affairs (MAE), the Provence-Alpes-Côte d'Azur region, the Aquitaine region, PAST, the National Research Foundation of South Africa, the University of Cape Town (Department of Archaeology), the French Institute of South Africa (IFAS) and the Centre National de la Recherche Scientifique (CNRS). Finally, we thank Francesco d'Errico, Enza Spinapolice and Kathryn Ranhorn for their valuable comments on an earlier draft of the manuscript. Version 3 of this preprint has been peer-reviewed and recommended by Peer Community In Archaeology (https://doi.org/10.24072/pci.archaeo.100006).

\section{Conflict of interest disclosure}

The authors of this article declare that they have no financial conflict of interest with the content of this article. Patrick Schmidt is one of the $\mathrm{PCl}$ Archaeology recommenders.

\section{References}

Anderson, H., 2012. Crossing the line: the early expression of pattern in Middle Stone Age Africa. Journal of World Prehistory 25, 183-204.

Archer, W., Pop, C.M., Gunz, P., McPherron, S.P., 2016. What is Still Bay? Human biogeography and bifacial point variability. Journal of Human Evolution 97, 58-72.

Bamforth, D.B., 1990. Settlement, raw material, and lithic procurement in the central Mojave desert. Journal of Anthropological Archaeology 9, 70-104.

Barham, L.S., 1987. The bipolar technique in southern Africa: a replication experiment. The South African Archaeological Bulletin, 45-50.

Binford, L.R., 1981. Bones. Ancient Men and Modern Myths. Academic Press: New York.

Blasco, R., Rosell, J., Cuartero, F., Fernandez Peris, J., Gopher, A., Barkai, R., 2013. Using bones to shape stones: MIS 9 bone retouchers at both edges of the Mediterranean sea. PLoS ONE 8, e76780. doi:10.1371/journal.pone.0076780

Boëda, E., 2013. Techno-logique \& Technologie. Une Paléo-histoire des objets lithiques tranchants. Paris: @rchéo-éditions.com.

Bouzouggar, A., Barton, N., Vanhaeren, M., d'Errico, F., Collcutt, S., Higham, T., Hodge, E., Parfitt, S., Rhodes, E., Schwenninger, J.L., Stringer, C., 2007. 82,000-year-old shell beads from North Africa and implications for the origins of modern human behavior. Proceedings of the National Academy of Sciences 104, 99649.

Brain, C.K., 1974. Some suggested procedures in the analysis of bone accumulations from southern African Quaternary sites. Annals of the Transvaal Museum 29, 1-8.

Bromage T.G., Boyde A., 1984. Microscopic criteria for the determination of directionality of cutmarks on bone. American Journal of Physical Anthropology 65, 359-66. 
Brown, K.S., Marean, C.W., Herries, A.I., Jacobs, Z., Tribolo, C., Braun, D., Roberts, D.L., Meyer, M.C., Bernatchez, J., 2009. Fire as an engineering tool of early modern humans. Science 325, 859-62.

Brown, K.S., Marean, C.W., Jacobs, Z., Schoville, B.J., Oestmo, S., Fisher, E.C., Bernatchez, J., Karkanas, P., Matthews, T., 2012. An early and enduring advanced technology originating 71,000 years ago in South Africa. Nature 491, 590.

Brugal, J.P., 2017. Classes de taille chez les grands mammifères. In: TaphonomieS, J.P. Brugal (dir.), Paris : Edition des Archives Contemporaines, Collection Sciences Archéologiques: 472-76.

Cahen, D., Keeley, L.H., 1980. Not less than two, not more than three. World Archaeology 12, 166-80.

Cartwright, C.R., 2013. Identifying the woody resources of Diepkloof Rock Shelter (South Africa) using scanning electron microscopy of the MSA wood charcoal assemblages. Journal of Archaeological Science 40, 3463-74.

Cavalli-Sforza, L.L., Feldman, M.W., 1981. Cultural transmission and evolution: A quantitative approach. Princeton University Press: 16.

Charrié-Duhaut, A., Porraz, G., Cartwright, C.R., Igreja, M., Connan, J., Poggenpoel, C., Texier, P.J., 2013. First molecular identification of a hafting adhesive in the late Howiesons Poort at Diepkloof Rock Shelter (Western Cape, South Africa). Journal of Archaeological Science 40, 3506-18.

Clark, J.L., Ligouis, B., 2010. Burned bone in the Howieson's Poort and post-Howieson's Poort Middle Stone Age deposits at Sibudu (South Africa): behavioral and taphonomic implications. Journal of Archaeological Science 37, 2650-61.

Cook, J., 1986. Marked human bones from Gough's Cave, Somerset. Proceedings of the University of Bristol Speleological Society 17, 275-85.

Conard, N.J., 2008. A critical view of the evidence for a southern African origin of behavioural modernity. Goodwin Series, 175-179.

Conard, N.J., Porraz, G., Wadley, L., 2012. What is in a name? Characterising the 'Post-Howieson's Poort' at Sibudu. South African Archaeological Bulletin 67, 180-99.

Creswell, R., 1994. La nature cyclique des relations entre le technique et le social. Approche technologique de la chaîne opératoire. In: B. Latour \& P. Lemonnier (Eds.), De la préhistoire aux missiles balistiques. L'intelligence sociale des techniques (pp. 275-289). Paris: Editions La découverte.

Dayet, L., Le Bourdonnec, F.X., Daniel, F., Porraz, G., Texier, P.J., 2016. Ochre provenance and procurement strategies during the middle stone age at Diepkloof Rock Shelter, South Africa. Archaeometry 58, 80729.

De Araujo Igreja, M., 1999. Relations entre l'outil et les modifications des matières dures animales. Approches expérimentale et archéologique sur ossements. Master Thesis, Université de Provence, UFR Civilisations et Humanités.

de Beaune, S., 2004. The invention of technology: prehistory and cognition. Current Anthropology 45, 139-62. de Beaune, S., 2012. Que nous dit la Préhistoire des conditions de l'invention ? Ivan Toulouse. Technique et Création. L'Harmattant: 53-70. Eurêka et Cie. 
Delagnes, A., Schmidt, P., Douze, K., Wurz, S., Bellot-Gurlet, L., Conard, N.J., Nickel, K.G., Van Niekerk, K.L., Henshilwood, C.S., 2016. Early evidence for the extensive heat treatment of silcrete in the Howiesons Poort at Klipdrift Shelter (Layer PBD, 65 ka), South Africa. PloS One 11, e0163874.

de la Penã, P., 2015. A qualitative guide to recognize bipolar knapping for flint and quartz. Lithic technology 40, 316-31.

d’Errico, F., 1991. Etude technologique à base expérimentale des entailles sur matière dure animale. In: 25 ans d'études technologiques en Préhistoires, Antibes, ed. APDCA, 83-97.

d'Errico, F., David, S., 1993. Analyse technologique de l'art mobilier. Le cas de l'abri des Cabônes à Ranchot (Jura). Gallia Préhistoire 35, 139-76.

d’Errico, F., Street, M., Sanchez Goni, M.F., 1994. L'art gravé azilien. De la technique à la signification. Gallia Préhistoire, Suppléments 31, 1-325.

d'Errico F., Villa, P., 1997. Holes and grooves: the contribution of microscopy and taphonomy to the problem of art origins. Journal of Human Evolution 33, 1-31.

d'Errico, F., Henshilwood, C., Nilssen, P., 2001. An engraved bone fragment from c. 70,000-year-old Middle Stone Age levels at Blombos Cave, South Africa: implications for the origin of symbolism and language. Antiquity 75, 309-18.

d'Errico, F., Henshilwood, C.S., 2007. Additional evidence for bone technology in the southern African Middle Stone Age. Journal of Human Evolution 52, 142-63.

d'Errico, F., Backwell, L.R., Wadley, L., 2012a. Identifying regional variability in Middle Stone Age bone technology: the case of Sibudu Cave. Journal of Archaeological Sciences 39, 2479-95.

d'Errico, F., Moreno, R.G., Rifkin, R.F., 2012b. Technological, elemental and colorimetric analysis of an engraved ochre fragment from the Middle Stone Age levels of Klasies River Cave 1, South Africa. Journal of Archaeological Science 39, 942-52.

d'Errico, F., Colagè, I. 2018. Cultural exaptation and cultural neural reuse: A mechanism for the emergence of modern culture and behavior. Biological Theory 13, 213-27.

Domanski, M., Webb, J.A., 1992. Effect of heat treatment on siliceous rocks used in prehistoric lithic technology. Journal of Archaeological Science 19, 601-14.

Domínguez-Rodrigo, M., De Juana, S., Galan, A.B., Rodriguez, M., 2009. A new protocol to differentiate trampling marks from butchery cut marks. Journal of Archaeological Science 36, 2643-53.

Domínguez-Rodrigo, M., Pickering, T.R., Bunn, H.T., 2010. Configurational approach to identifying the earliest hominin butchers. Proceedings of the National Academy of Sciences 107, 20929-34.

Driver, J., 2005. Thickness coding sheet for Crow Canyon Archaeological Center fauna through 2008. DOI: 10.6067/XCV89S1PCK.

Durham, W. H., 1991. Coevolution: Genes, culture, and human diversity. Stanford University Press.

Fiorillo, A. R., 1989. An experimental study of trampling: implications for the fossil record. Bone modification, 61-71. 
Fisher, J., 1995. Bone surface modification in zooarcheology. Journal of Archaeological Method and Theory 2, 7-68.

Foley, R.A., Mirazón Lahr, M., 2011. The evolution of the diversity of cultures. Philosophical Transactions of the Royal Society B: Biological Sciences 366, 1080-9.

Fritz, C., 1999. La gravure dans l'art mobilier magdalénien ? Du geste à la représentation. Paris : Maison des Sciences de l'Homme.

Galán, A.B., Domínguez-Rodrigo, M., 2013. An experimental study of the anatomical distribution of cut marks created by filleting and disarticulation on the long bone ends. Archeometry 55, 1132-49.

Gille, B., 1978. Histoire des techniques. Paris, Gallimard, Bibliothèque de la Pléiade.

Gould, S.J., Vrba, E.S., 1982. Exaptation-a missing term in the science of form. Paleobiology. 8, 4-15.

Gravina, B., Discamps E., 2015. MTA-B or not to be? Recycled bifaces and shifting hunting strategies at Le Moustier and their implication for the late Middle Palaeolithic in southwestern France. Journal of Human Evolution 84, 83-98.

Henrich J., 2015. The secret of our success: how learning from others drove human evolution, domesticated our species, and made us smart. Princeton Univ Press, Princeton.

Henrich, J., McElreath, R., 2003. The evolution of cultural evolution. Evolutionary Anthropology: Issues, News, and Reviews 12, 123-35.

Henshilwood, C.S., d'Errico, F., Yates, R., Jacobs, Z., Tribolo, C., Duller, G.A., Mercier, N., Sealy, J.C., Valladas, H., Watts, I., Wintle, A.G, 2002. Emergence of modern behavior: Middle Stone Age engravings from South Africa. Science 295, 1278-80.

Henshilwood, C., d'Errico, F., Vanhaeren, M., Van Niekerk, K., \& Jacobs, Z. 2004. Middle Stone Age shell beads from South Africa. Science 304, 404.

Henshilwood, C.S., d'Errico, F., Watts, I., 2009. Engraved ochres from the Middle Stone Age levels at Blombos Cave, South Africa. Journal of Human Evolution 57, 27-47.

Henshilwood, C. S., d'Errico, F., 2011. Homo symbolicus: the dawn of language, imagination and spirituality. John Benjamins Publishing.

Henshilwood, C.S., van Niekerk, K.L., Wurz, S., Delagnes, A., Armitage, S.J., Rifkin, R.F., Douze, K., Keene, P., Haaland, M.M., Reynard, J., Discamps, E., 2014. Klipdrift shelter, southern Cape, South Africa: preliminary report on the Howiesons Poort layers. Journal of Archaeological Science 45, 284- 303.

Henshilwood, C.S., d'Errico, F., van Niekerk, K.L., Dayet, L., Queffelec, A., Pollarolo, L., 2018. An abstract drawing from the 73,000-year-old levels at Blombos Cave, South Africa. Nature 562, 115.

Jacobs, Z., Roberts, R.G., Galbraith, R.F., Deacon, H.J., Grün, R., Mackay, A., Mitchell, P., Vogelsang, R., Wadley, L., 2008. Ages for the Middle Stone Age of southern Africa: implications for human behavior and dispersal. Science 322, 733-5.

Jacobs, Z., Roberts, R.G., 2015. An improved single grain OSL chronology for the sedimentary deposits from Diepkloof Rock Shelter, Western Cape, South Africa. Journal of Archaeological Science 63, 175-92. 
Jacobs, Z., Roberts, R.G., 2017. Single-grain OSL chronologies for the Still Bay and Howieson's Poort industries and the transition between them: Further analyses and statistical modelling. Journal of Human Evolution 107, 1-13.

Juana de, S., Galan, A.B., Domínguez-Rodrigo, M., 2010. Taphonomic identification of cutmark made with lithic handaxes: an experimental study. Journal of Archaeological Science 37, 1841-50.

Kornprobst, J., 2002. Metamorphic Rocks and Their Geodynamic Significance. A Petrological Handbook, Kluwer Academic Publishers, Dordrecht.

Kuhn, S.L., 1995. Mousterian lithic technology: an ecological perspective. Princeton University Press.

Kuhn, S.L., 2012. Emergent patterns of creativity and innovation in early technologies. Developments in Quaternary Sciences 16, 69-87.

Le Brun-Ricalens, F., 2006. Les pièces esquillées : état des connaissances après un siècle de reconnaissance. PALEO 18, 95-114.

Lemonnier, P., 1993. Technological choices: Transformation in material cultures since the Neolithic. London: Routledge.

Lombard, M., Phillipson, L., 2010. Indications of bow and stone-tipped arrow use 64000 years ago in KwaZuluNatal, South Africa. Antiquity 84, 635-48.

Lyman R.L., 1987. Archaeofaunas and butchery studies: a taphonomic perspective. In: M.B. Schiffer (ed.), Advances in Archaeological Method and Theory. New-York, Academic Press 10, 249-337.

Lyman, R.L., 1994. Vertebrate Taphonomy. Cambridge University Press: Cambridge.

Mallye, J.B., Thiébaut, C., Mourre, V., Costamagno, S., Claud, É., Weisbecker, P., 2012. The Mousterian bone retouchers of Noisetier Cave: experimentation and identification of marks. Journal of Archaeological Science 39, 1131-42.

Marean, C.W., Bar-Matthews, M., Bernatchez, J., Fisher, E., Goldberg, P., Herries, A.I., Jacobs, Z., Jerardino, A., Karkanas, P., Minichillo, T., Nilssen, P.J., 2007. Early human use of marine resources and pigment in South Africa during the Middle Pleistocene. Nature 449, 905-8.

Maté-González, M.A., Yravedra, J., González-Aguilera, D., Palomeque-González, J.F., DomínguezRodrigo, M., 2015. Micro-photogrammetric characterization of cut marks on bones. Journal of Archaeological Science $62,128-142$.

McBrearty, S., Brooks, A.S., 2000. The revolution that wasn't: a new interpretation of the origin of modern human behavior. Journal of Human Evolution 39, 453-563.

McElreath, R., 2010. The coevolution of genes, innovation, and culture in human evolution. In: Silk, J., Kappeler, P. (Eds.), Mind the gap: tracing the origins of human universals. Springer, Berlin, Heidelberg, 451-474.

Meignen, L., 1982. Supports d'outils chauffés au Paléolithique moyen. In: Cahen, D. (Ed.), Tailler! Pour quoi faire. Préhistoire et technologie lithique II. Recent progress in microwear studies, Studia Praehistorica Belgica 2, 111-7.

Mesoudi, A., 2016. Cultural evolution: a review of theory, findings and controversies. Evolutionary biology 43, 481-497. 
Mesoudi, A., Whiten, A., Laland, K.N., 2004. Perspective: Is human cultural evolution Darwinian? Evidence reviewed from the perspective of The Origin of Species. Evolution 58, 1-11.

Miller, C.E., Goldberg, P., Berna, F., 2013. Geoarchaeological investigations at Diepkloof Rock Shelter, Western Cape, South Africa. Journal of Archaeological Science 40, 3432-52.

Morales Pérez, J.V., Brugal, J.Ph., Pérez Ripoll, M., Galván Santos, B., Hernández, C., 2008. La fracturación y fragmentación de huesos largos durante el paleolítico. una aproximación teórica y metodológica. In: Rovira Llorens, S., García-Heras, M., Gener Moret, M., Montero Ruiz, I. (Eds.), Actas VII Congresso lobérico de Arqueometria, Madrid, 8-10 de octubre 2007, S1: Biomateriales, 64-76.

Monnier, G.F., Bischoff, E., 2014. Size matters. An evaluation of descriptive and metric criteria for identifying cut marks made by unmodified rocks during butchery. Journal of Archaeological Science 50, 305-317.

Mourre, V., Villa, P., Henshilwood, C.S., 2010. Early use of pressure flaking on lithic artifacts at Blombos Cave, South Africa. Science 330, 659-62.

Oliver, J.S., 1989. Analogues and site context: bone damages from Shield Trap cave (24CB91), Carbon county, Montana, USA. In: Bonnichsen, R., and Sorg, M.H. (Eds.), Bone Modification. Center for the study of the first Americans, Orono, Univ. of Maine, 73-98.

Olsen, S.L., Shipman, P., 1988. Surface modifications on bone: trampling vs butchery. Journal of Archaeological Science 15, 535-553.

Palomeque-González, J.F., Maté-González, M.A., Yravedra, J., Juan-Blazquez, M.S., García Vargas, E., MartínPerea, D.M., Estaca-Gómez, V., González-Aguilera, D., Domínguez-Rodrigo, M., 2017. Pandora: A new morphometric and statistical software for analysing and distinguishing cut marks on bones. Journal of Archaeological Science: Reports 13, 60-66.

Pargeter, J., Schmidt, P., 2020. 'Simple' surface-fire heat treatment significantly improves silcrete flake quality and flaking efficiency. Journal of Archaeological Science: Reports 30, 102203.

Parkington, J.E., Rigaud, J.P., Poggenpoel, C., Porraz, G., Texier, P.J., 2013. Introduction to the project and excavation of Diepkloof Rock Shelter (Western Cape, South Africa): a view on the Middle Stone Age. Journal of Archaeological Science 40, 3369-75.

Parkington, J.E., Porraz, G., 2016. Elands Bay Cave and the stone age of the Verlorenvlei, South Africa. Southern African Humanities 29, KwaZulu-Natal Museum.

Porraz, G., 2005. En marge du milieu alpin-Dynamiques de formation des ensembles lithiques et modes d'occupation des territoires au Paléolithique moyen. Ph. D. Dissertation, University of Aix-Marseille, France.

Porraz, G., 2009. Middle Paleolithic mobile toolkits in short term human occupations: two case studies. Eurasian Prehistory 6, 33-55.

Porraz, G., Texier, P.J., Archer, W., Piboule, M., Rigaud, J.P, Tribolo, C. 2013. Technological successions in the Middle Stone Age sequence of Diepkloof Rock Shelter, Western Cape, South Africa. Journal of Archaeological Science 40, 3376-3400. 
Porraz, G., Texier, J.P. Miller, C.E., 2014. Le complexe bifacial Still Bay et ses modalités d'émergence à l'abri Diepkloof (Middle Stone Age, Afrique du Sud). In: XXVIlème Congrès Préhistorique de France, Transitions, Ruptures et Continuité en Préhistoire. Mémoires de la Société Préhistorique Française, 155175.

Porraz, G., Igreja, M., Schmidt, P., Parkington, J.E., 2016. A shape to the microlithic Robberg from Elands Bay Cave (South Africa). Southern African Humanities 29, 203-247.

Porraz, G., Val, A., Tribolo, C., Mercier, N., de La Peña, P., Haaland, M.M., Igreja, M., Miller, C.E., Schmid, V.C. 2018. The MIS5 Pietersburg at '28' Bushman Rock Shelter, Limpopo Province, South Africa. PloS One 13, e0202853.

Reynard, J.P., Badenhorst, S., Henshilwood, C.S., 2014. Inferring animal size from the unidentified long bones from the Middle Stone Age layers at Blombos Cave, South Africa. Annals of the Ditsong National Museum of Natural History 4, 9-25.

Rots, V., Plisson, H., 2014. Projectiles and the abuse of the use-wear method in a search for impact. Journal of Archaeological Science 48, 154-165.

Rots, V., Lentfer, C., Schmid, V.C., Porraz, G., Conard, N.J., 2017. Pressure flaking to serrate bifacial points for the hunt during the MIS5 at Sibudu Cave (South Africa). PloS One 12, e0175151.

Roux, V., 2010. Technological innovations and developmental trajectories: social factors as evolutionary forces. Innovation in cultural systems. Contributions from evolutionary anthropology, 217-234.

Roux, V., 2013. Spreading of innovative technical traits and cumulative technical evolution: continuity or discontinuity? Journal of Archaeological Methods and Theory 20, 312-30.

Schmid, V., 2019. The CA layers of Sibudu Cave (KwaZulu-Natal, South Africa) in the light of the MSA lithic technologies in MIS 5. Ph. D. Dissertation, University of Tuebingen, Germany.

Schmid, V.C., Porraz, G., Zeidi, M., Conard, N.J., 2019. Blade Technology Characterizing the MIS 5 DA Layers of Sibudu Cave, South Africa. Lithic Technology 44, 199-236.

Schmid, V.C., Conard, N.J., Parkington, J.E., Texier, P.J., Porraz, G., 2016. The 'MSA 1' of Elands Bay Cave (South Africa) in the context of the southern African Early MSA technologies. Southern African Humanities 29, 153-201.

Schmidt, P., 2019. How reliable is the visual identification of heat treatment on silcrete? A quantitative verification with a new method. Archaeological and Anthropological Sciences 11, 713-26.

Schmidt, P., Porraz, G., Slodczyk, A., Bellot-Gurlet, L., Archer, W., Miller, C.E., 2013. Heat treatment in the South African Middle Stone Age: temperature induced transformations of silcrete and their technological implications. Journal of Archaeological Sciences 40, 3519-31.

Schmidt, P., Porraz, G., Bellot-Gurlet, L., February, E., Ligouis, B., Paris, C., Texier, P.J., Parkington, J.E., Miller, C.E., Nickel, K.G., Conard, N.J., 2015. A previously undescribed organic residue sheds light on heat treatment in the Middle Stone Age. Journal of Human Evolution. 85, 22-34. 
Schmidt, P., February, E., Bretzke, K., Bellot-Gurlet, L., 2016. Tempering-residue on heat-treated silcrete: an experimental perspective and a potential analytical protocol. Journal of Archaeological Science: Reports 15, 611-9.

Schmidt, P., Mackay, A., 2016. Why was silcrete heat-treated in the Middle Stone Age? An early transformative technology in the context of raw material use at Mertenhof Rock Shelter, South Africa. PloS One 11, e0149243.

Schmidt, P., Lauer, C., Buck, G., Miller, C.E., Nickel, K.G., 2017. Detailed near-infrared study of the 'water'related transformations in silcrete upon heat treatment. Physics and Chemistry of Minerals 44, 21-31.

Schmidt, P., Högberg, A., 2018. Heat treatment in the Still Bay - A case study on Hollow Rock Shelter, South Africa. Journal of Archaeological Science: Reports 21, 712-20.

Schmidt, P., Buck, G., Berthold, C., Lauer, C., Nickel, K., 2019. The mechanical properties of heat-treated rocks: a comparison between chert and silcrete. Archaeological and Anthropological Sciences 11, 2489-2506.

Schmidt, P., Stynder, D., Conard, N., Parkington, J., 2020. When was silcrete heat treatment invented in South Africa? Palgrave Communications accepted for publication 31/03/2020, DOI: 10.1057/s41599020-0454$z$.

Shennan, S., 2001. Demography and cultural innovation: a model and its implications for the emergence of modern human culture. Cambridge Archaeological Journal 11, 5-16.

Shipman, P., 1981. Application of scanning electron microscopy to taphonomic problems. In: A. M. Cantwell, A.M., Griffin, J.B., Rothschild, N. (Eds) The Research Potential of Anthropological Museum Collections, pp. 357-385. Annals of the New York Academy of Sciences 276, New York.

Shipman, P., Rose, J., 1983. Early hominid hunting, butchering, and carcass-processing behaviors: approaches to the fossil record. Journal of Anthropological Archaeology 2, 57-98.

Simondon, G., 2005. L'invention dans les techniques: cours et conférences. Traces écrites, Editions du Seuil.

Singer, R., Wymer, J., 1982. The Middle Stone Age at Klasies River Mouth in South Africa. University of Chicago Press.

Soriano, S., Villa, P., Delagnes, A., Degano, I., Pollarolo, L., Lucejko, J.J., Henshilwood, C., Wadley, L., 2015. The Still Bay and Howiesons Poort at Sibudu and Blombos: understanding Middle Stone Age technologies. PloS One 10, e0149243.

Soulier, M.-C., Mourin, E., 2016. Cutmark data and their implications for the planning depth of Late Pleistocene societies. Journal of Human Evolution 97, 37-57.

Steele, T.E., Klein, R.G., 2013. The Middle and Later Stone Age faunal remains from Diepkloof Rock Shelter, Western Cape, South Africa. Journal of Archaeological Science 40, 3453-62.

Stiner, M.C., Kuhn, S., Weiner, S., Bar-Yosef, O., 1995. Differential burning, recrystallization and fragmentation of archaeological bone. Journal of Archaeological Science 22, 223-37.

Stuart-Fox, M., 2015. Rethinking the evolution of culture and cognitive structure. Journal of Cognition and Culture 15, 109-30. 
Texier, P.J., Porraz, G., Parkington, J., Rigaud, J.P., Poggenpoel, C., Miller, C., Tribolo, C., Cartwright, C., Coudenneau, A., Klein, R., Steele, T., Verna, C., 2010. A Howiesons Poort tradition of engraving ostrich eggshell containers dated to 60,000 years ago at Diepkloof Rock Shelter, South Africa. Proceedings of the National Academy of Sciences 107, 6180-5.

Texier, P.J., Porraz, G., Parkington, J., Rigaud, J.P., Poggenpoel, C., Tribolo, C., 2013. The context, form and significance of the MSA engraved ostrich eggshell collection from Diepkloof Rock Shelter, Western Cape, South Africa. Journal of Archaeological Science 40, 3412-31.

Thiébaut, C., Claud, É., Costamagno, S. (Dir.), 2019. Procurement and processing of plant and animal materials by Neanderthals: exploring means and strategies. Results of a study based on an experimental approach and the archaeological analysis of several sites in Western Europe, carried out in the context of the "Des traces et des Hommes" PCR. Palethnology, Archaeology and Humanities.

Tomasso, A., Porraz, G., 2016. Hunter-gatherer mobility and embedded raw-material procurement strategies in the Mediterranean Upper Paleolithic. Evolutionary Anthropology 25, 164-74.

Tribolo, C., Mercier, N., Douville, E., Joron, J.L., Reyss, J.L., Rufer, D., Cantin, N., Lefrais, Y., Miller, C.E., Porraz, G., Parkington, J., 2013. OSL and TL dating of the Middle Stone Age sequence at Diepkloof Rock Shelter (South Africa): a clarification. Journal of Archaeological Science 40, 3401-11.

Turq, A., Roebroeks, W., Bourguignon, L., Faivre, J.-PH., 2013. The fragmented character of Middle Palaeolithic stone tool technology. Journal of Human Evolution. 65, 641-55.

Val, A., 2019. New data on avifaunal remains associated with the Middle Stone Age layers from Diepkloof Rock Shelter, Western Cape, South Africa. Journal of Archaeological Science: Reports 26, 101880.

Val, A., Porraz, G., Texier, P.J., Fisher, J.W., Parkington, J., 2020. Human exploitation of nocturnal felines at Diepkloof Rock Shelter provides further evidence for symbolic behaviours during the Middle Stone Age. Science Reports 10, 6424.

Vanhaeren, M., d'Errico, F., Van Niekerk, K.L., Henshilwood, C.S., Erasmus, R.M., 2013. Thinking strings: additional evidence for personal ornament use in the Middle Stone Age at Blombos Cave, South Africa. Journal of human evolution 64, 500-17.

Vaquero, M., Alonso, S., García-Catalán, S., García-Hernández, A., de Soler, B.G., Rettig, D., Soto, M. 2012. Temporal nature and recycling of Upper Paleolithic artifacts: the burned tools from the Molídel Salt site (Vimbodíi Poblet, northeastern Spain). Journal of Archaeological Science 39, 2785-96.

Villa, P., Mahieu, E., 1991. Breakage patterns of human long bones. Journal of Human Evolution 21, 27-48.

Volman, T.P., 1984. Early prehistory of southern Africa. In: Klein, R.G. (Ed.), Southern Africa Prehistory and Paleoenvironments. A.A. Balkema.

Wadley, L., 2010. Compound-adhesive manufacture as a behavioral proxy for complex cognition in the Middle Stone Age. Current Anthropology 51, 111-19.

Wadley, L., 2015. Those marvellous millennia: the Middle Stone Age of southern Africa. Azania: Archaeological Research in Africa 50, 155-226. 


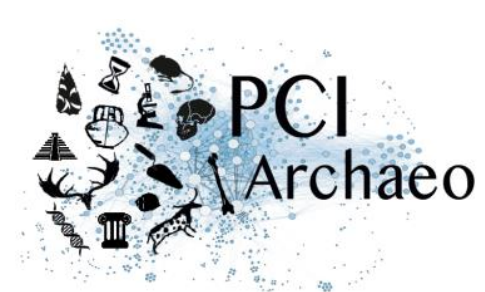

Wadley, L., Sievers, C., Bamford, M., Goldberg, P., Berna, F., Miller, C., 2011. Middle Stone Age bedding construction and settlement patterns at Sibudu, South Africa. Science 334, 1388-91.

Wadley, L., Prinsloo, L.C., 2014. Experimental heat treatment of silcrete implies analogical reasoning in the Middle Stone Age. Journal of Human Evolution 70, 49-60.

Watts, I., Chazan, M., Wilkins, J., 2016. Early Evidence for Brilliant Ritualized Display: Specularite Use in the Northern Cape (South Africa) between 500 and 300 Ka. Current Anthropology 57, 287-310.

White, T.D. 1992. Prehistoric Cannibalism at Mancos 5MTUMR-2346. Princeton University, Princeton.

Wilkins, J., Schoville, B.J., Brown, K. S., Chazan, M., 2012. Evidence for early hafted hunting technology. Science $338,942-6$.

Wurz, S.J.D., 2000. The Middle Stone Age at Klasies River, South Africa. Ph. D. Dissertation, University of Stellenbosch, South Africa.

Wurz, S., 2002. Variability in the Middle Stone Age lithic sequence, 115,000-60,000 years ago at Klasies River, South Africa. Journal of Archaeological Science 29, 1001-15. 